\title{
Wave and tidally driven flows in eelgrass beds and their effect on sediment suspension
}

\author{
Jennifer C. R. Hansen, Matthew A. Reidenbach* \\ Department of Environmental Sciences, University of Virginia, Charlottesville, Virginia 22904, USA
}

\begin{abstract}
Seagrass beds alter their hydrodynamic environment by inducing drag on the flow, thereby attenuating wave energy and near-bottom currents. This alters the turbulent structure and shear stresses within and around the seagrass bed that are responsible for the suspension and deposition of sediment. To quantify these interactions, velocity, pressure, and sediment measurements were obtained across a density gradient of an eelgrass Zostera marina bed within a shallow coastal bay ( 1 to $2 \mathrm{~m}$ depth). Eelgrass beds were found to reduce near-bottom mean velocities by 70 to $90 \%$, while wave heights were reduced 45 to $70 \%$ compared to an adjacent unvegetated region. Wave orbital velocities within the eelgrass bed were reduced by $20 \%$ compared to flow above the bed, primarily acting as a low-pass filter by removing high-frequency wave motion. However, relatively little reduction in wave energy occurred at lower wave frequencies, suggesting that longer period waves were able to effectively penetrate the seagrass meadow. Average bottom shear stresses $\left(\tau_{\mathrm{b}}\right)$ at the unvegetated region were $\tau_{\mathrm{b}}=0.17 \pm 0.08 \mathrm{~N} \mathrm{~m}^{-2}$, significantly larger than the critical stress threshold necessary for sediment entrainment of $0.04 \mathrm{~N} \mathrm{~m}^{-2}$. Within the eelgrass bed, $\tau_{\mathrm{b}}=0.03 \pm 0.02 \mathrm{~N} \mathrm{~m}^{-2}$ and stresses were below the critical stress threshold during $80 \%$ of the time period of measurement. Expansion of eelgrass within the coastal bay has thus altered the dynamics of the seafloor from an erosional environment to one that promotes deposition of suspended sediment, enhancing light penetration throughout the water column and creating a positive feedback for eelgrass growth.
\end{abstract}

KEY WORDS: Zostera marina - Seagrass · Waves - Turbulence · Boundary layer · Sediment resuspension

Resale or republication not permitted without written consent of the publisher

\section{INTRODUCTION}

Seagrass ecosystems have been viewed as depositional environments for sediment because the structure of the meadow serves to reduce flow and attenuate bottom shear stresses (Ward et al. 1984, Koch et al. 2006, Gruber \& Kemp 2010). Studies of direct particle trapping by seagrasses and seagrass epiphytes confirm that seagrass meadows buffer against sediment resuspension and increase sediment retention, therefore reducing erosion in the coastal zone (Gacia \& Duarte 2001, Agawin \& Duarte 2002). When fluid flow encounters individual seagrass blades or a seagrass bed, drag is imparted on the flow and a velocity gradient develops, creating a boundary layer (Denny 1988). Momentum loss due to drag by the canopy leads to the reduction in resuspension; however, reduced resuspension and increased sediment accumulation may not occur at the same rate everywhere within the meadow, and are dependent upon local flow dynamics and sediment supply from within and outside the meadow (Chen et al. 2007). Whether bulk flow is able to move through the seagrass canopy or is diverted above or around it is dependent on shoot density and bed spatial heterogeneity (Fonseca \& Koehl 2006, Nepf et al. 2007). Reduction in velocities within seagrass beds is often accompanied by skimming flow, which increases velocities above the sea- 
grass canopy relative to ambient flow conditions (Fonseca et al. 1982). This creates an inflection point of instability in the velocity profile, and shear layers are developed near the top of the canopy (Widdows et al. 2008, Bouma et al. 2009), which can locally enhance turbulent mixing into the canopy (Nepf \& Vivoni 2000). Canopy friction exhibits a strong positive relationship to the percent of the water column occupied by the seagrass (Fonseca \& Fisher 1986), and greater flow reductions are found inside canopies with increasing shoot density (Peterson et al. 2004). However, the impact of seagrass on withincanopy turbulence is less clear, and suggests that mixing rates and turbulent kinetic energy (TKE) are highly dependent upon seagrass density and morphology (Worcester 1995, Granata et al. 2001, Widdows et al. 2008).

Within shallow-water environments where seagrasses are abundant, local flow dynamics can be drastically altered depending on whether currents are dominated by tides, wind-generated waves, storm surge, or a combination of these factors (Fonseca \& Cahalan 1992, Koch \& Gust 1999, Koch et al. 2006). The increase in oscillatory flows caused by waves has been linked to enhanced turbidity (Granata et al. 2001). The nonlinear interaction between waves and currents leads to changes in the hydrodynamics and shear stresses imposed on the seafloor from those expected under either condition independently (Jing \& Ridd 1996). Typically when waves are present in unvegetated seafloor regions, an oscillatory wave boundary layer develops that is more strongly sheared than the boundary layer formed under steady conditions alone (Grant \& Madsen 1979). This wave boundary layer results in greater drag on the mean flow and increased bottom shear stresses. Sediment resuspension has been found to be predominately controlled by waves in shallow coastal bays, occurring periodically and corresponding to high wind events (Lawson et al. 2007), suggesting sediment suspension is episodic in nature. Many studies have described how seagrasses attenuate waves (Fonseca \& Cahalan 1992, Koch \& Gust 1999, Bradley \& Houser 2009); however, how this attenuation impacts bottom shear stresses and within-canopy turbulence, which are ultimately responsible for the suspension of sediments from the seafloor, is largely unknown.

Most studies that have addressed the impacts of seagrass density and morphology on flow and sediment dynamics have been based on laboratory flume experiments or numerical modeling (Heller 1987, Chen et al. 2007, Bouma et al. 2009, Carr et al. 2010).
These studies have determined that the thickness of the shear layer at the top of the canopy is directly related to the vegetation density; as density is increased under a constant velocity, the exchange is reduced, as is the penetration depth of the mixed layer into the canopy (Ghisalberti \& Nepf 2002). For waves that are typically generated in fetch-limited shallow coastal bays, wave energy decreases with depth, and the magnitude of wave energy that reaches the seafloor depends heavily on the wave period, wave height, and overall water depth (de Boer 2007). According to modeling efforts, wave energy attenuation increases with increasing shoot density (Chen et al. 2007), but the degree of flow reduction by the canopy can also be a function of distance from the edge of the canopy and the mean depth at which the seagrass resides below the surface (Fonseca \& Fisher 1986, Verduin \& Backhaus 2000). However, the lack of field studies on these interactions makes it difficult to understand the role of seagrass structure on near-bottom turbulence, bottom shear, and sediment dynamics (de Boer 2007). Consequently, it is important to explore the dynamic interactions between seagrass meadows and fluid motion on multiple spatial and temporal scales.

Within the coastal bays of Virginia, USA, the oncedominant seagrass species Zostera marina (eelgrass) virtually disappeared during the 1930s due to a pandemic infestation of a parasitic fungus, called wasting disease, combined with a destructive hurricane (Short et al. 1987, Orth et al. 2006). The discovery of several small, natural patches of eelgrass in the mid-1990s suggested that certain locations within the coastal bays were adequate for plant growth (Orth et al. 2006). Survival and expansion of these plots initiated an intensive, large-scale eelgrass seeding program to re-establish the Virginia coastal bays (Fig. 1) as a self-sustaining seagrass ecosystem (Orth et al. 2012, this Theme Section). The shallow depths of Virginia coastal bays, typically $<2 \mathrm{~m}$ depth, make the bottom sediments susceptible to current- and waveinduced sediment suspension. These coastal bays also lack any significant riverine discharge, and therefore turbidity is primarily controlled by local resuspension (Lawson et al. 2007). In addition, low pelagic primary productivity in the coastal bays suggests that light attenuation is primarily controlled by non-algal particulate matter (Sand-Jensen \& Borum 1991, McGlathery et al. 2001). High suspended sediment concentrations (SSC) can attenuate light penetration through the water column that can limit benthic primary production (Zimmerman et al. 1995). As a result, subsequent changes in the fluid environ- 
Fig. 1. Study sites, located off the eastern shore of the Delmarva peninsula, Virginia, USA. The 4 study sites within and outside the eelgrass bed are labeled on the aerial image of South Bay. Location of the eelgrass bed within South Bay is outlined in white. Bare: a predominantly unvegetated site

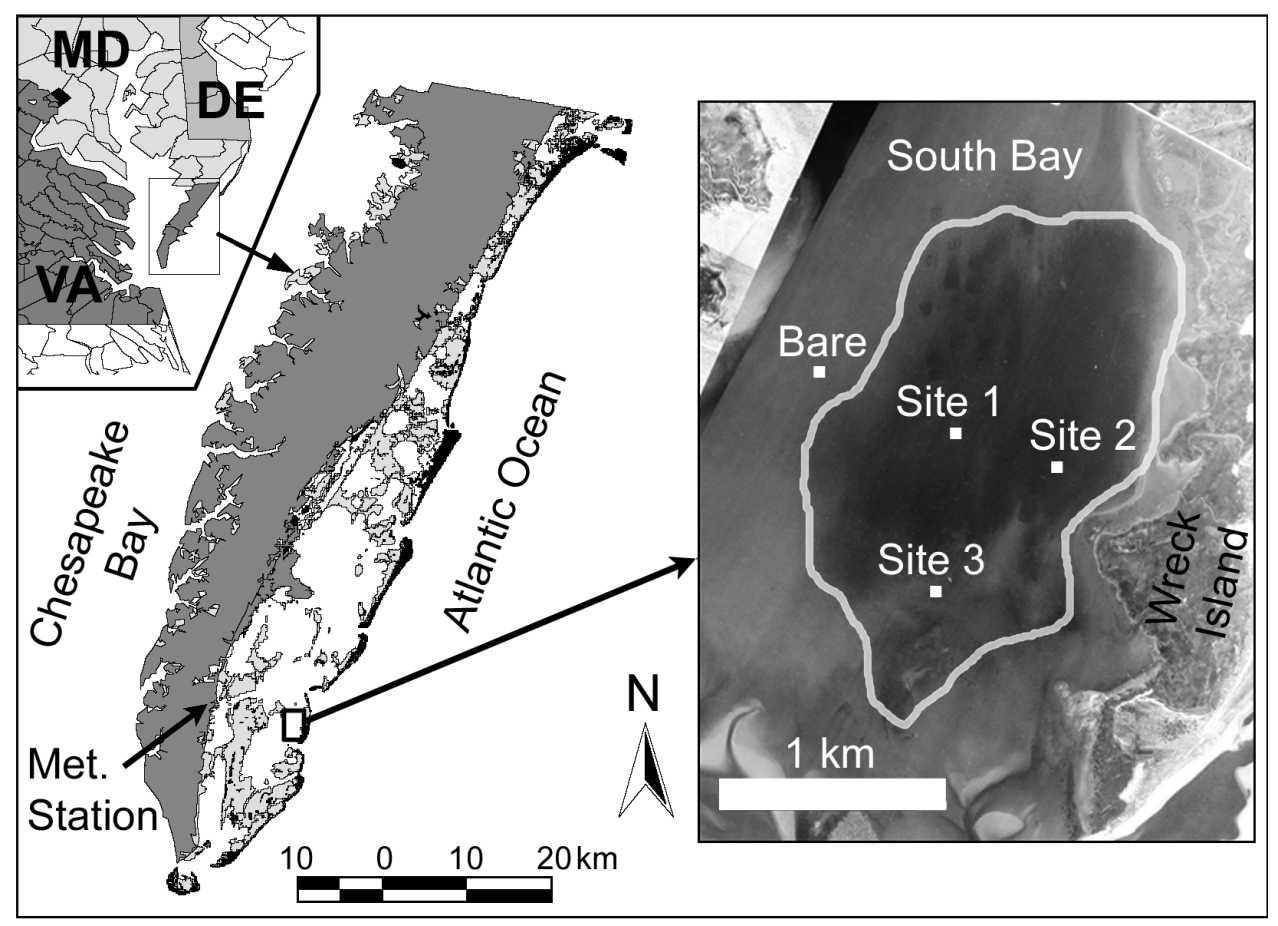

ment due to the eelgrass expansion now being observed in these coastal bays (Orth et al. 2012, this Theme Section) may improve water quality and reduce turbidity, thus increasing light penetration to the seafloor, which has been shown to have a positive feedback effect on seagrass growth (Madsen et al. 2001, Carr et al. 2010).

In coordination with the seagrass seeding program, the focus of the present study was on the relationships between physical and biological forces controlling water circulation, flow structure, and suspended sediment within the seagrass beds and the Virginia coastal bay system. The goals were to quantify: (1) the spatial variation of Zostera marina morphology across the meadow, (2) the velocity and turbulence levels above and within the Z. marina canopy, (3) the bottom shear stresses due to combined currents and waves, (4) and the response of the SSC to local turbulence and shear stress magnitudes. These parameters were compared to flow and sediment dynamics occurring in an adjacent unvegetated region.

\section{MATERIALS AND METHODS}

Seagrass studies were performed in South Bay, one of the coastal bays within the Virginia Coast Reserve (VCR), where ongoing seagrass restoration efforts are being performed. The VCR is characterized by contiguous marsh, shallow bay, and barrier island systems and is a National Science Foundation-Long Term Ecological Research (NSF-LTER) program site (Fig. 1). Reseeding of eelgrass Zostera marina in South Bay began in 2001 (Orth et al. 2012, this Theme Section). Field studies were performed in May and June of 2010, with instrument deployments and field data collection occurring over a $72 \mathrm{~h}$ period at each site. Three seagrass sites were chosen of varying density, each surrounded by a $Z$. marinadominated area of at least $700 \mathrm{~m}^{2}$. During summer 2010, the total eelgrass cover in South Bay was estimated to be 1020 ha (Orth et al. 2012, this Theme Section). A predominantly unvegetated site, containing only very few, small patches of eelgrass within the region, was also monitored as a reference for flow characteristics in the absence of any considerable benthic vegetation ('Bare' in Fig. 1). Eelgrass density was measured in the field via $0.25 \mathrm{~m}^{2}$ quadrat shoot counts, while blade length and width were measured in the laboratory from eelgrass collected at each site (Table 1). The 3 sites, labeled Sites 1, 2, and 3 in Fig. 1 , contained $Z$. marina of varying densities of $560 \pm 70,390 \pm 80$, and $150 \pm 80$ shoots $\mathrm{m}^{-2}$, respectively. Mean blade lengths ranged from 16 to $28 \mathrm{~cm}$. Densities between each of the 3 sites, as well as mean blade lengths, were significantly different from one another (ANOVA, $\mathrm{p}<0.05$ ). Measurements were taken throughout 3 consecutive weeks from June to July 2010, a period in the growing season when the eelgrass is near peak biomass (Orth et al. 2006). 
Table 1. Zostera marina. Morphometrics during the summer of 2010 at 3 neighboring sites in South Bay, Virginia, USA. Eelgrass density was measured using in situ $0.25 \mathrm{~m}^{2}$ quadrat shoot counts. Blade length is the mean length of all eelgrass blades measured, maximum length is the average of the longest $10 \%$ of all blades, and blade width was measured at the midpoint along the length of the blade. Values are $\pm \mathrm{SD}$. $\mathrm{n}_{\text {blades: }}$ number of blades measured for length and width; $\mathrm{n}_{\text {density }}$ : number of $0.25 \mathrm{~m}^{2}$ quadrats measured

\begin{tabular}{|llccrcr|}
\hline & $\begin{array}{c}\text { Blade } \\
\text { length } \\
(\mathrm{cm})\end{array}$ & $\begin{array}{c}\text { Max. } \\
\text { length } \\
(\mathrm{cm})\end{array}$ & $\begin{array}{c}\text { Blade } \\
\text { width } \\
(\mathrm{cm})\end{array}$ & $\begin{array}{c}\mathrm{n}_{\text {blades }} \\
(\text { shoots m }\end{array}$ & & \\
& & & & & \\
\hline Site 1 & $21 \pm 8$ & $33 \pm 3$ & $0.29 \pm 0.08$ & 158 & $560 \pm 70$ & 9 \\
Site 2 & $28 \pm 13$ & $51 \pm 3$ & $0.41 \pm 0.12$ & 176 & $390 \pm 80$ & 8 \\
Site 3 & $16 \pm 9$ & $34 \pm 4$ & $0.26 \pm 0.07$ & 73 & $150 \pm 80$ & 21 \\
\hline
\end{tabular}

Mean water depth at all study sites ranged between 1.4 and $1.8 \mathrm{~m}$. Bathymetry for the coastal bays throughout the VCR is provided in Fagherazzi \& Wiberg (2009).

\section{Instrumentation}

A coordinated package of instrumentation was deployed at each site for a minimum of $72 \mathrm{~h}$. Two Nortek Vector acoustic Doppler velocimeters (ADVs) were deployed at each site, and velocity was quantified at a single point within a $1 \mathrm{~cm}^{3}$ sampling volume located $15 \mathrm{~cm}$ below each sensor. One ADV was located within the meadow with its sampling volume at $z=$ $0.1 \mathrm{~m}$ above the seafloor, and the other ADV was located above the meadow with its sampling volume at $z=0.5 \mathrm{~m}$. To measure velocities within the meadow, a small eelgrass patch of $15 \mathrm{~cm}$ diameter (the size of the instrument probe) was removed to prevent blades from blocking the sampling volume. In addition, values with poor correlation factors, often due to the probes being exposed at low tide, were removed. Velocities were measured at each site in 10 min bursts every $20 \mathrm{~min}$ at a sampling rate of $32 \mathrm{~Hz}$. Each ADV was equipped with a pressure sensor, which was used to determine the water depth and characterize the wave climate. Wind data were obtained from a meteorological station in Oyster, Virginia, located approximately $4 \mathrm{~km}$ from South Bay (Fig. 1).

Sediment grain size distribution was characterized at each site using a laser diffraction particle size analyzer (Beckman Coulter LS I3 320). Sediment samples were sieved at $1 \mathrm{~mm}$ to remove large organic matter, such as eelgrass blades and roots, and then bleached to remove particulate organic matter. The size class distribution was found, and $D_{84}$, the grain size diame- ter for which $84 \%$ of the sample grain diameters are smaller, was computed from the resulting size distribution curve. At least 2 samples were collected and analyzed from each site. Sediment $D_{84}$ at the bare site was $157 \pm 7 \mu \mathrm{m}$, while, at the eelgrass sites, sediments were finer at $130 \pm 17 \mu \mathrm{m}$. SSCs were measured using 2 optical backscatter sensors (OBSs; Campbell Scientific OBS3+). One OBS was placed within the meadow to quantify SSC at $z=0.1 \mathrm{~m}$, and another, above the canopy at $z=0.5 \mathrm{~m}$, where $z$ is the vertical distance above the seafloor. To perform laboratory calibrations of the OBS, sediment samples were collected, suspended, and known volumes of suspended sediment were mixed into 601 of filtered seawater. Suspended sediment sample volumes were then dried and weighed, and a linear regression was formed between the backscatter intensity from the OBS and the SSC. Each calibration had an $\mathrm{R}^{2}>0.99$.

\section{Wave-turbulence decomposition}

Instantaneous velocity measurements were collected in the east-north-up (ENU) reference frame using the internal compass and tilt sensors of the velocimeters and were time-averaged independently for every $10 \mathrm{~min}$ burst interval. Velocities were then rotated for each burst interval into the dominant direction of horizontal flow, $u$. Mean velocity and turbulence statistics were computed along the dominant flow direction $(u)$, transverse direction $(v)$, and vertical direction $(w)$. The 10 min time interval was chosen because in statistical tests, 10 min often emerges as the best balance between obtaining convergence of the mean statistics while minimizing velocity drift due to changes in flow conditions (Gross \& Nowell 1983).

In flows with both waves and currents, the variance in velocity associated with waves is often much larger than that associated with turbulence and some form of wave-turbulence decomposition must be performed (Trowbridge 1998). When waves and currents are present, the instantaneous horizontal and vertical velocities can be written as:

$$
\begin{aligned}
& u=u^{\prime}+\tilde{u}+\bar{u} \\
& w=w^{\prime}+\tilde{w}+\bar{w}
\end{aligned}
$$

where $\bar{u}$ and $\bar{w}$ are the horizontal and vertical components of the mean velocity, $\tilde{u}$ and $\tilde{w}$ are the waveinduced orbital velocities, and $u^{\prime}$ and $w^{\prime}$ are the turbulent velocities. To determine motions that contribute to the turbulent Reynolds stress, $\overline{u^{\prime} W^{\prime}}$, turbulent motions must be separated from those of waves. The method of wave-turbulence decomposition that 
was employed uses spectral decomposition, known as the phase method (Bricker \& Monismith 2007), where the phase lag between the $u$ and $w$ components of the surface waves are used to interpolate the magnitude of turbulence under the wave peak. The wave stress is calculated through the spectral sum:

$$
\overline{\tilde{u} \tilde{W}}=\int_{-f_{\text {NYquist }}}^{f_{\text {Nyquist }}} S_{\tilde{u} \tilde{W}}(f) \mathrm{d}(f)
$$

where $S_{\tilde{u} \tilde{w}}(f)$ is the 2-sided cross-spectral density (CSD) of the wave-induced orbital velocities, $f$ is frequency and $f_{N_{y} q u i s t}$ is the Nyquist sampling frequency, which is half the sampling frequency of the discrete signal. The turbulence spectrum can be expressed as the difference between the spectrum of raw velocities and that of wave-induced orbital velocities such that:

$$
\mathrm{S}_{u^{\prime} W^{\prime}}(f)=\mathrm{S}_{u w}(f)-\mathrm{S}_{\tilde{u} \tilde{w}}(f)
$$

The CSD of the spectra in Eq. (3) are then integrated to obtain the turbulent Reynolds stress:

$$
\overline{u^{\prime} w^{\prime}}=\overline{u w}-\overline{\tilde{u} \tilde{w}}
$$

$U_{j}=U\left(f_{j}\right)$ and $W_{j}=W\left(f_{j}\right)$ are the Fourier transforms of $u(t)$ and $w(t)$ at the frequency $f_{j}$ in the Fourier transform. For a finite data series, the integral of the wave stress becomes:

$$
\overline{\tilde{u} \tilde{W}}=\sum_{j=-N / 2}^{j=N / 2} \tilde{U}_{j} \times \tilde{W}_{j}
$$

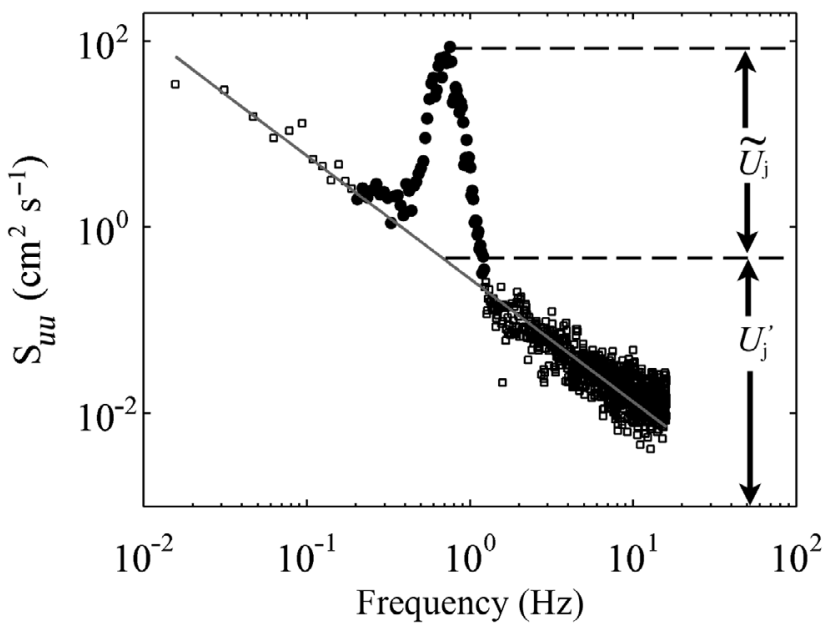

Fig. 2. Power spectral density (PSD) of the horizontal velocity, $S_{u u}$ for a $10 \mathrm{~min}$ representative data series computed at $z=0.1 \mathrm{~m}$ at the bare site, where $z$ is the vertical distance above the seafloor. Solid circles: region encompassing wave peak; squares: region of the spectra outside the wave domain. Grey solid line: least squares fit to the data outside the wave domain. The wave component of the stress is removed by subtracting the PSD formed above the grey line that encompasses the region of the wave peak where $N$ is the number of data points used in the Fourier transform and the magnitude of $\tilde{W}_{j}$ is the difference between the raw $W_{j}$ and the turbulence $W_{j}^{\prime}$ interpolated below the wave peak, via a leastsquared fit straight line, as shown in Fig. 2. The magnitude of $\tilde{W}_{j}$ is the difference between the raw $W_{j}$ and the turbulence $W_{j}^{\prime}$ interpolated below the wave peak, via a least-squared fit straight line, as shown in Fig. 2. $\tilde{W}_{j}$ is solved for by expressing the wave stress in terms of power spectral density (PSD):

$$
S_{w w_{j}}=\frac{1}{\mathrm{~d} f}\left|W_{j}\right|^{2}
$$

The same method is used to solve for $\tilde{U}_{j}$. The Fourier coefficients can be written in phasor notation as:

$\overline{\tilde{u} \tilde{W}}=\sum_{j=\text { wave_peak }} \tilde{U}_{j} \times \tilde{W}_{j}=\sum_{j=\text { wave_peak }}\left|\tilde{U}_{j}\right|\left|\tilde{W}_{j}\right| \cos \left(\angle W_{j}-\angle U_{j}\right)$

where $\angle W_{j}$ and $\angle U_{j}$ are the phases of the Fourier coefficients. The wave stress is then found by integrating the wave component of the CSD, $S_{\tilde{u} \tilde{w}}(f)$, over the width of the wave peak and subtracting it from the integral of the total stress, $S_{u w}(f)$, over the full frequency spectrum in order to obtain Reynolds stress, as in Eq. (4).

\section{Wave orbital velocities}

The spectral density of surface elevation, $S_{\eta \eta p}$, was computed using the pressure signal from the ADV located at $z=0.5 \mathrm{~m}$ as:

$$
S_{\eta \eta p}=\left[\frac{\cosh (k h)}{\cosh (k z)}\right]^{2} \frac{S_{\mathrm{pp}}}{\rho^{2} g^{2}}
$$

where $S_{\mathrm{pp}}$ is the spectral density of the pressure, $k$ is the wave number $\left(\mathrm{m}^{-1},=2 \pi / L\right.$ where $L$ is wavelength), $h$ is the mean water depth, $z$ is the vertical distance above the seafloor, $g$ is gravitational acceleration and $\rho$ is density (Dean \& Dalrymple 1991). Significant wave height $\left(H_{\mathrm{s}}\right)$ and average period $(T)$ were then computed using the first $(m 0)$ and second (m2) moments from the $S_{\eta \eta p}$ power spectrum:

$$
H_{s}=4 \sqrt{m 0} \quad T=\sqrt{m 0 / m 2}
$$

where $m 0=\int S_{\eta \eta p}(f) \mathrm{d}(f)$ and $m 2=\int f^{2} S_{\eta \eta p}(f) \mathrm{d}(f)$.

To determine the interaction between eelgrass structure and wave-induced flows, wave orbital velocities were calculated and compared above and within the eelgrass meadow. Adjacent to the sea 
floor, vertical orbital velocity approaches zero and thus the horizontal component of the orbital velocity accounts for the majority of particle motion. The horizontal orbital velocity can be calculated from spectra of the horizontal velocity components, $u$ and $v$, by summing the contributions from wave spectra across each frequency component (Wiberg \& Sherwood 2008):

$$
u_{\mathrm{os}}^{2}=2\left[\sum_{j} S_{\tilde{u} \tilde{u}_{j}} \Delta f_{j}+\sum_{j} S_{\tilde{v} \tilde{v}_{j}} \Delta f_{j}\right]
$$

where $u_{0 s}$ is equivalent to the root-mean-squared (rms) orbital velocity. Since only the wave spectra are used and not the full spectrum, this method removes water motion due to turbulence and currents driven by the tides. Eq. (10) can then be applied to velocities above and within the canopy to determine seagrass impacts on orbital wave motion.

\section{RESULTS}

Physical characteristics of wind speed, water temperature and depth, as well as depth-averaged water currents, significant wave height, and SSCs measured at each Zostera marina site are shown in Fig. 3. The bay had a mean depth of approximately $1.6 \mathrm{~m}$, and the average wind speed between May and June 2010 was $2.3 \pm 1.2 \mathrm{~m} \mathrm{~s}^{-1}$. Over the course of the sampling period, water temperatures in the bay steadily increased from 21 to $30^{\circ} \mathrm{C}$. The flow regime in South Bay was tidally dominated; therefore, water veloci- ties were low at high and low tide and intensified during ebbing and flooding tides. In addition, flows were typically not symmetric, with ebbing tides characterized by slightly higher velocity magnitudes than flooding tides. Mean tidal amplitude and significant wave height at each site are shown in Fig. 4A. Tidal amplitudes ranged from 0.58 to $0.73 \mathrm{~m}$, while $H_{\mathrm{s}}$ ranged from $0.18 \pm 0.08 \mathrm{~m}$ at the bare site to $0.05 \pm$ $0.02 \mathrm{~m}$ at eelgrass Site 3 . Time-averaged velocities at $z=0.5$ and $0.1 \mathrm{~m}$ at each site are shown in Fig. 4B. The bare site showed a $40 \%$ reduction in velocity between $z=0.5$ and $0.1 \mathrm{~m}$ due to frictional interaction with the seafloor. In comparison, velocities within the seagrass canopy $(z=0.1 \mathrm{~m})$ showed a $70 \%$ reduction in velocity compared to $\mathrm{z}=0.5 \mathrm{~m}$ due to the combined influence of friction by the seafloor and drag induced by the seagrass canopy.

Waves within these coastal bays were predominately formed by winds, the $H_{\mathrm{s}}$ of which is controlled by the fetch and bottom topography over which they propagate (Lawson et al. 2007). At the bare site, strong winds were mostly to the north. During these periods, wind-generated waves traveled over stretches of South Bay devoid of eelgrass, with average wind speeds ( $\pm 1 \mathrm{SD}$ ) of $2.6 \pm 1.4 \mathrm{~m} \mathrm{~s}^{-1}$. At the eelgrass sites, there were no consistent patterns in the wind direction, with winds oscillating from northward to southward (Fig. 3A). Average wind conditions at Sites 1, 2, and 3 were $2.3 \pm 1.2,2.4 \pm 1.1$, and $1.9 \pm 1.0 \mathrm{~m} \mathrm{~s}^{-1}$, respectively. For all sites, there was a minimum of $5 \mathrm{~km}$ of fetch to both the north and

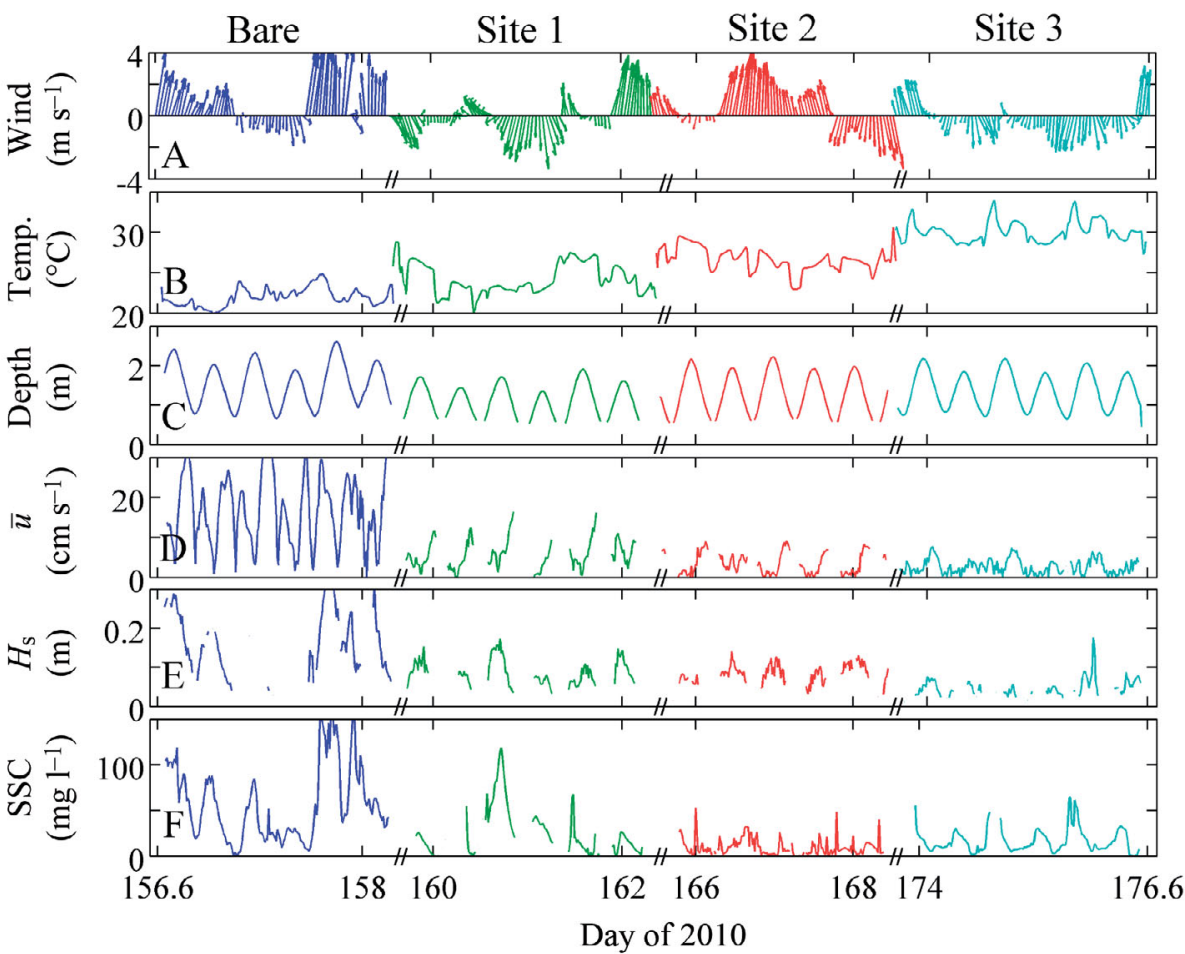

Fig. 3. (A) Wind magnitude and direction, (B) water temperature, (C) water depth, (D) magnitude of burst-averaged water speed $(\bar{u})$ at $z$ (vertical distance above the seafloor) $=0.5 \mathrm{~m}$, (E) significant wave height $\left(H_{\mathrm{s}}\right)$, and $(\mathrm{F})$ suspended sediment concentration (SCC) at $z=0.1 \mathrm{~m}$. Locations of missing or no data correspond to time periods when velocimeters or sediment sensors had poor signal quality. Note the non-continuous time record, where days between successive monitoring of sites have been removed 

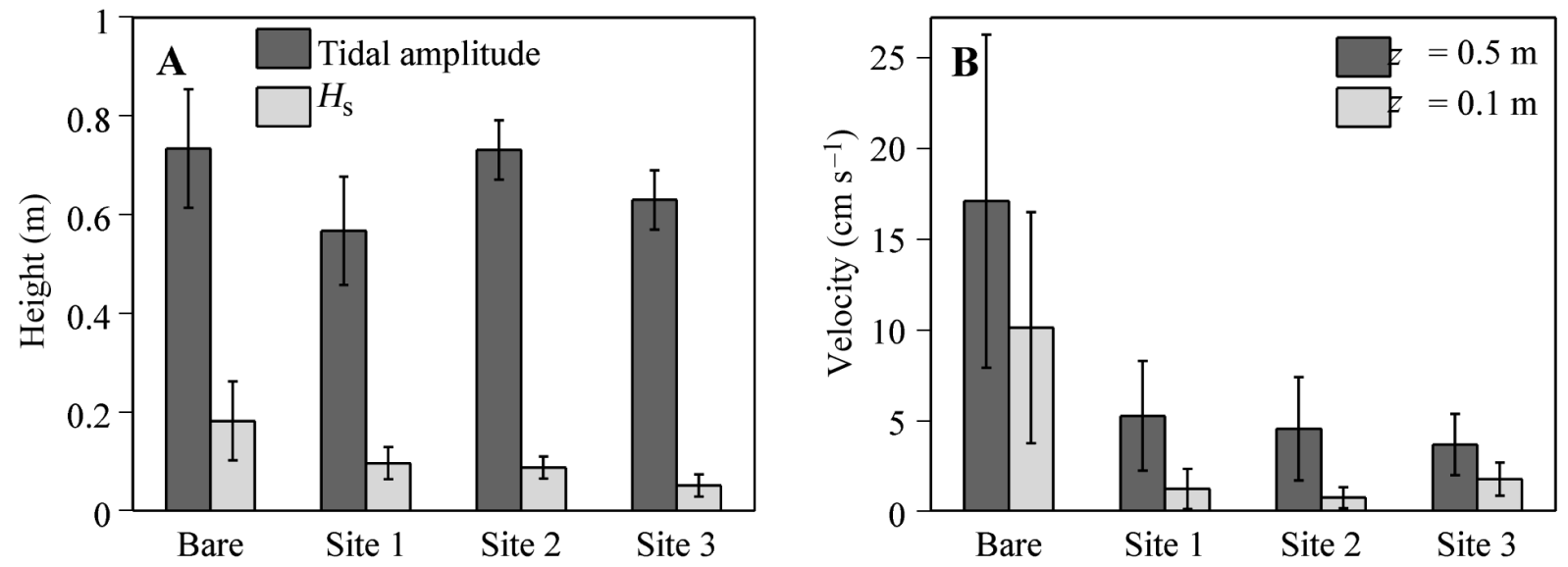

Fig. 4. (A) Average tidal amplitudes and significant wave heights $\left(H_{\mathrm{s}}\right)$ with error bars representing \pm 1 SD. The average across all sites was $0.65 \pm 0.11 \mathrm{~m}$. (B) Time-averaged velocity magnitude of the study sites during tidally dominant flow conditions $( \pm 1 \mathrm{SD})$. $z$ : vertical distance above the seafloor

south. $H_{\mathrm{s}}$ increased at all sites during periods surrounding high tide and was reduced during low tide (Fig. 3E). Overall, there was a 45 to $70 \%$ reduction in measured $H_{\mathrm{s}}$ at the eelgrass sites compared to the bare site, although changes in wind magnitude and direction during sampling played a factor in wave development and the overall amount of wave reduction (Fig. 5). In general, the rate of increase in $H_{\mathrm{s}}$ with increasing wind speed was considerably smaller at the eelgrass sites than at the bare site.

\section{Turbulent kinetic energy and Reynolds stress}

At each site, flows were separated into time periods where wave action was a significant contributor to the overall flow and those with minimal wave action where flows were dominated by tidally driven currents. Tidally dominated flows were those where the PSD of the wave component of the frequency spectrum, $S_{\tilde{u} \tilde{w}}$ constituted $<10 \%$ of the overall power density, $S_{u w}$ measured at $z=0.5 \mathrm{~m}$. Overall, at the bare site, tidally dominated flows occurred $15 \%$ of the time, while, at the eelgrass sites, due to wave attenuation across the canopy, tidally dominated flows occurred approximately $25 \%$ of the time. There was no statistical difference in time-averaged mean velocity during periods in which tidally dominated or wavedominated flows occurred. Both Reynolds stress $\left(\overline{u^{\prime} W^{\prime}}\right)$ and turbulent kinetic energy, TKE $=0.5\left(u^{\prime 2}+\right.$ $v^{\prime 2}+W^{\prime 2}$ ), were computed at each site (Fig. 6), where $u^{\prime}, v^{\prime}$, and $w^{\prime}$ are the turbulent velocity fluctuations in the dominant horizontal, transverse, and vertical directions, respectively.. At the bare site during tidally dominated time periods, Reynolds stresses, $\overline{u^{\prime} W^{\prime}}$, were similar at the $z=0.5$ and $0.1 \mathrm{~m}$ elevations, whereas there was up to a $60 \%$ reduction in Reynolds stress magnitude at the eelgrass sites. Although standard deviations for TKE and Reynolds stress were large at all locations, this was primarily due to variations in velocity magnitude caused by waves and tides. Confidence intervals for mean estimates were typically quite small, and locations where significant differences were found between mean estimates of TKE and $\overline{u^{\prime} w^{\prime}}$ at $z=0.1$ and $0.5 \mathrm{~m}$ are denoted with an asterisk in Fig. 6. Comparisons of $\overline{u^{\prime} w^{\prime}}$ within the canopy versus that above the canopy at each site indicated that the largest reduction in $\overline{u^{\prime} W^{\prime}}$ coincided with the

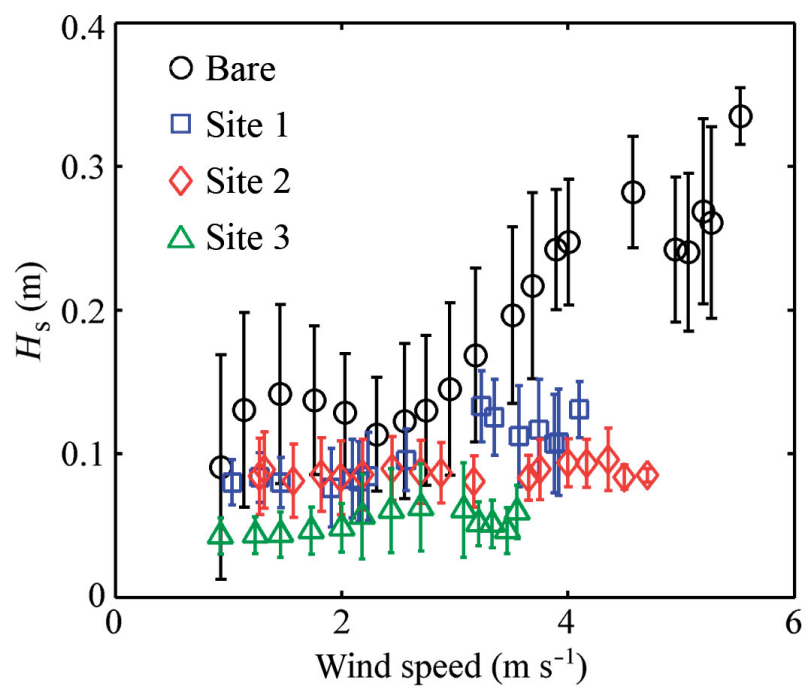

Fig. 5. Significant wave height $\left(H_{\mathrm{s}}\right)$ as a function of mean wind speed. Bars represent $\pm 1 \mathrm{SD}$. Estimates of $H_{\mathrm{s}}$ were computed as running means over a $\pm 0.5 \mathrm{~m} \mathrm{~s}^{-1}$ averaging window of wind speed 
most dense eelgrass canopy, Site 1, followed by the mid-density, Site 2, and then the most sparse canopy, Site 3. TKE also showed reductions within the canopy versus above the canopy, but the magnitude of the reduction was significantly less than that of the Reynolds stress. This may be due to the added stem-generated TKE formed by flow interaction with the seagrass blades (Verduin \& Backhaus 2000).

To compute Reynolds stress and TKE for wavedominated flow conditions, the wave components of the PSD were first removed, as in Eq. (3), and then the remaining turbulent component of the PSD was integrated. Overall, the addition of waves did not statistically alter the magnitude of Reynolds stress or TKE at either the bare site or eelgrass sites (Fig. 6C,D). Reynolds stress was typically reduced within the seagrass canopy compared to above the canopy, although trends of greater reductions of within-canopy $\overline{u^{\prime} w^{\prime}}$ with higher seagrass densities were not as evident under wave-dominated conditions as they were in tidally dominated flows.
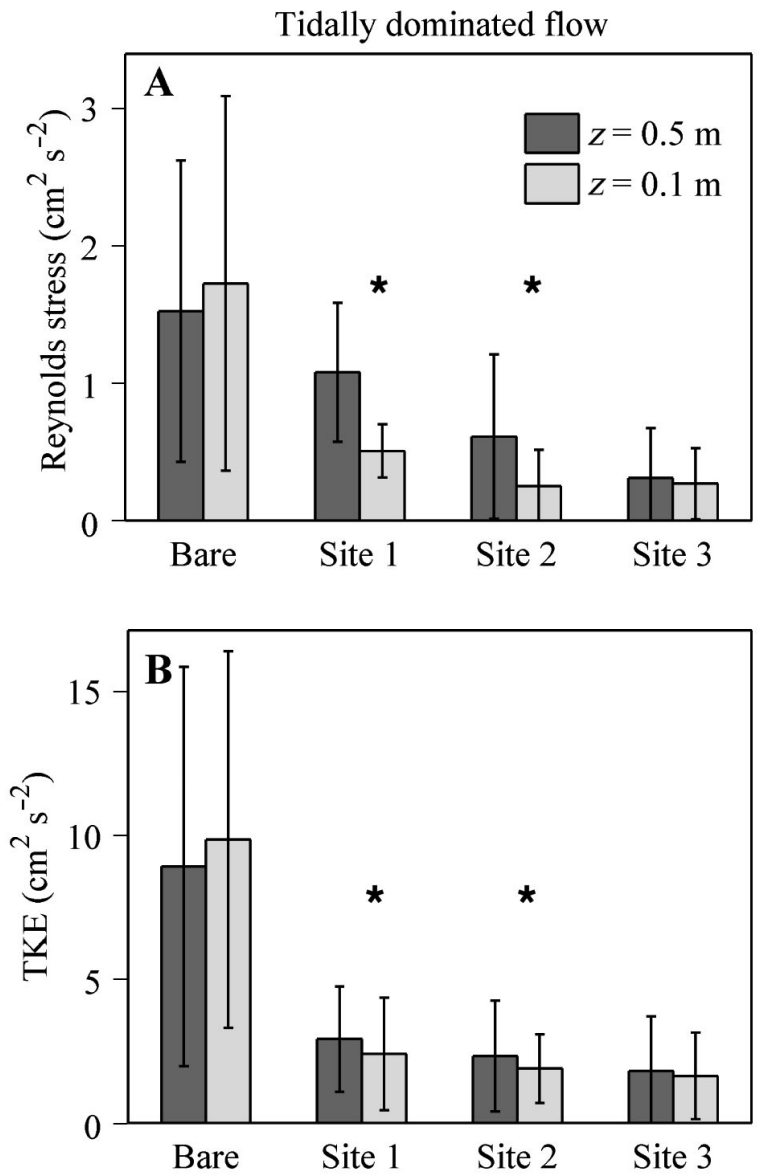

\section{Quadrant analysis of turbulence}

Quadrant analysis is a useful technique to describe how turbulent fluctuations contribute to the transport of momentum, sediment, and gases throughout the bottom boundary layer (Lu \& Willmarth 1973). Depending upon the flow field, highmomentum fluid overlaying the seagrass canopy can be advected downwards into the canopy, or low-momentum fluid residing within the canopy can be advected upwards out of the canopy. Velocity fluctuations, $u^{\prime}$ and $w^{\prime}$, were normalized by their respective standard deviations and were divided into 4 quadrants based on the sign of their instantaneous values. Contours of the turbulent probability distribution function (pdf) are shown in Fig. 7 for turbulent motions within and above the eelgrass bed at Site 1 during periods with no wave action. Quadrants are listed from Q1 to Q4. The 2 dominant quadrants responsible for momentum transfer are Q2 $\left(u^{\prime}<0, w^{\prime}>0\right)$, where turbulent
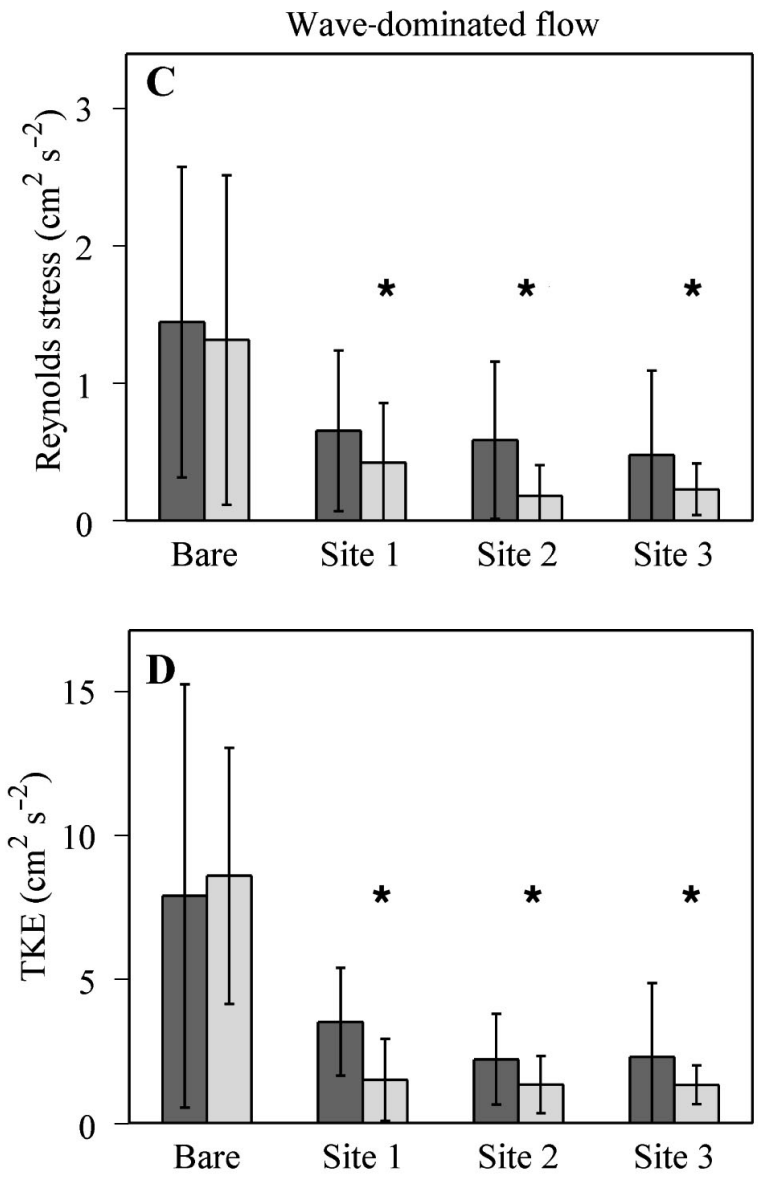

Fig. 6. (A) Reynolds stress $\left(-\overline{u^{\prime} W^{\prime}}, \pm 1 \mathrm{SD}\right),(\mathrm{B})$ turbulent kinetic energy (TKE, $\pm 1 \mathrm{SD}$ ) for tidally dominated flow conditions, (C) Reynolds stress and (D) TKE for wave-dominated flow conditions. * Locations where confidence intervals of mean estimates were significantly different between $z$ (vertical distance above the seafloor) $=0.1$ and $0.5 \mathrm{~m}$ 

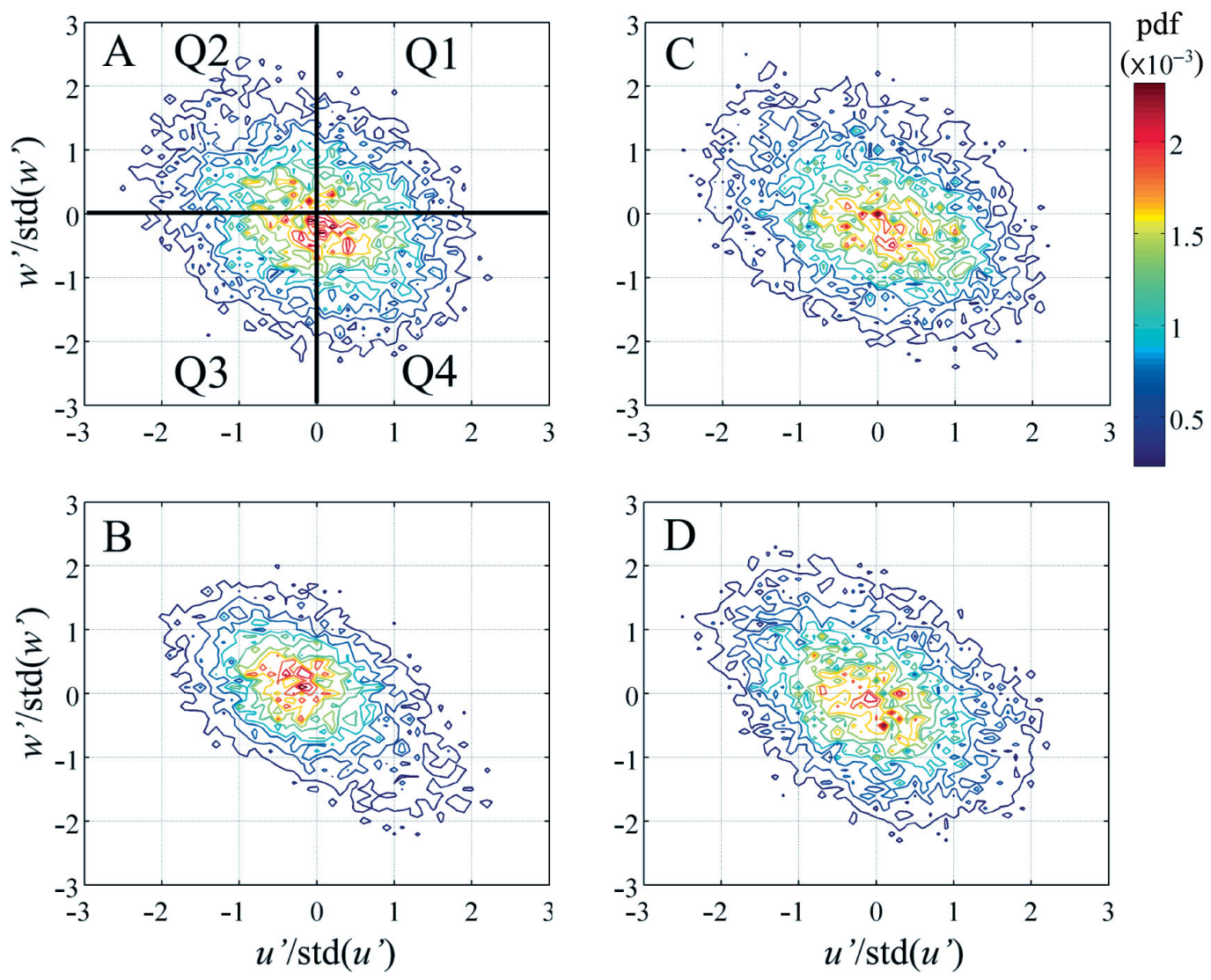

Fig. 7. Quadrant analysis of the probability density functions (pdf) of $u^{\prime}$ and $w^{\prime}$ distributions normalized by their standard deviation (std) at (A,B) Zostera marina Site 1 for (A) $z$ (vertical distance above the seafloor) $=0.5 \mathrm{~m}$ and (B) $z=0.1 \mathrm{~m}$, showing the dominance of turbulent sweeping events in Quadrant $4(\mathrm{Q} 4)$, and at $(\mathrm{C}, \mathrm{D})$ the bare site for $(\mathrm{C}) \mathrm{z}=0.5 \mathrm{~m}$ and $(\mathrm{D}) \mathrm{Z}=0.1 \mathrm{~m}$

ejections of low-momentum fluid are transported vertically upwards, and Q4, where sweeping events transport high-momentum fluid downward towards the seagrass meadow. These ejection/ sweep phenomena result in intermittent flushing of water masses from within the canopy (Grass 1971). Typically, momentum transport is dominated by ejection and sweeping events and shows a predominance of values in Q2 and Q4, which held true for flows above the eelgrass canopy (Fig. 7A). The total contribution to Reynolds stress within each quadrant was found by summing the absolute value of the $u^{\prime} w^{\prime}$ contributions within each quadrant and dividing by the total contribution from all quadrants: Q1 (15\%), Q2 (36\%), Q3 (15\%), and Q4 (34\%). This indicated that the combined Q2 and Q4 contributions accounted for approximately $70 \%$ of the total Reynolds stress, which is similar to results determined in other studies of flow over high-roughness topographies (Bennet \& Best 1996, Lacey \& Roy 2008). There was a fairly even distribution of stresses between Q2 and Q4, indicating that the turbulent ejection of low-momentum fluid from near the top of the seagrass canopy was similar to that of sweeps of high-momentum fluid towards the canopy.

Within the seagrass canopy, at $z=0.1 \mathrm{~m}$, distinct changes in the contribution to the stress from various components occurred (Fig. 7B), where motions within Q4 were dominant. The total contribution to Reynolds stress within each quadrant was: Q1 (7\%), Q2 (32\%), Q3 (6\%), and Q4 (55\%). This signifies that the principal exchange of water masses within the canopy was driven by sweeps of high-momentum fluid from above the canopy downwards into the canopy. For the bare site (Fig. $7 \mathrm{C}, \mathrm{D}$ ), there was still dominance in Q2 and Q4, with 75 and $79 \%$ of the total Reynolds stresses found at $z=0.5$ and $0.1 \mathrm{~m}$, respectively. However, there was a fairly even distribution of stresses between Q2 and Q4 at both elevations, similar to the flow structure formed above the seagrass canopy. For instance at $z=0.1 \mathrm{~m}$, contributions were: Q1 (11\%), Q2 (40\%), Q3 (10\%), and Q4 $(39 \%)$. 


\section{Velocity spectra and wave orbitals}

PSDs of the horizontal velocities during tidally dominated flow conditions at the bare site showed a distinct $-5 / 3$ slope, indicative of an inertial subrange at both $z=0.1$ and $0.5 \mathrm{~m}$ (Fig. 8A). There was general agreement between the 2 elevations, with slightly higher energy at low frequencies $(<1 \mathrm{~Hz})$ for $z=$ $0.5 \mathrm{~m}$, indicative of higher mean flows, but lower energy at higher frequencies $(>1 \mathrm{~Hz})$, indicating lower turbulent energy within the inertial subrange. Within the eelgrass meadow, there was a reduction in the magnitude of the PSD across all frequencies within the canopy compared to flow above the canopy (Fig. 8B).

PSD of wave-dominated flow conditions showed similar trends outside the wave domain of the fre- quency spectrum for both the bare and eelgrass sites. Within the wave domain at the bare site (Fig. 8C), there was little wave energy attenuation, indicating that oscillatory motion due to waves was effective at generating wave-induced orbital motions near the seafloor. Within the wave domain at the eelgrass site (Fig. 8D), wave energy was still able to penetrate the eelgrass canopy, with little reduction of wave energy at $z=0.1 \mathrm{~m}$ at frequencies smaller than the wave peak. However, at both the bare and eelgrass sites, but especially within the Zostera marina canopy (Fig. 8D), the bulk of energy loss occurred at wave frequencies within the wave domain at approximately $f \geq 1 \mathrm{~Hz}$, where short period wave oscillations $(T=1 / f)$ attenuated before reaching the bottom. This agrees with wave theory that suggests waves will attenuate before
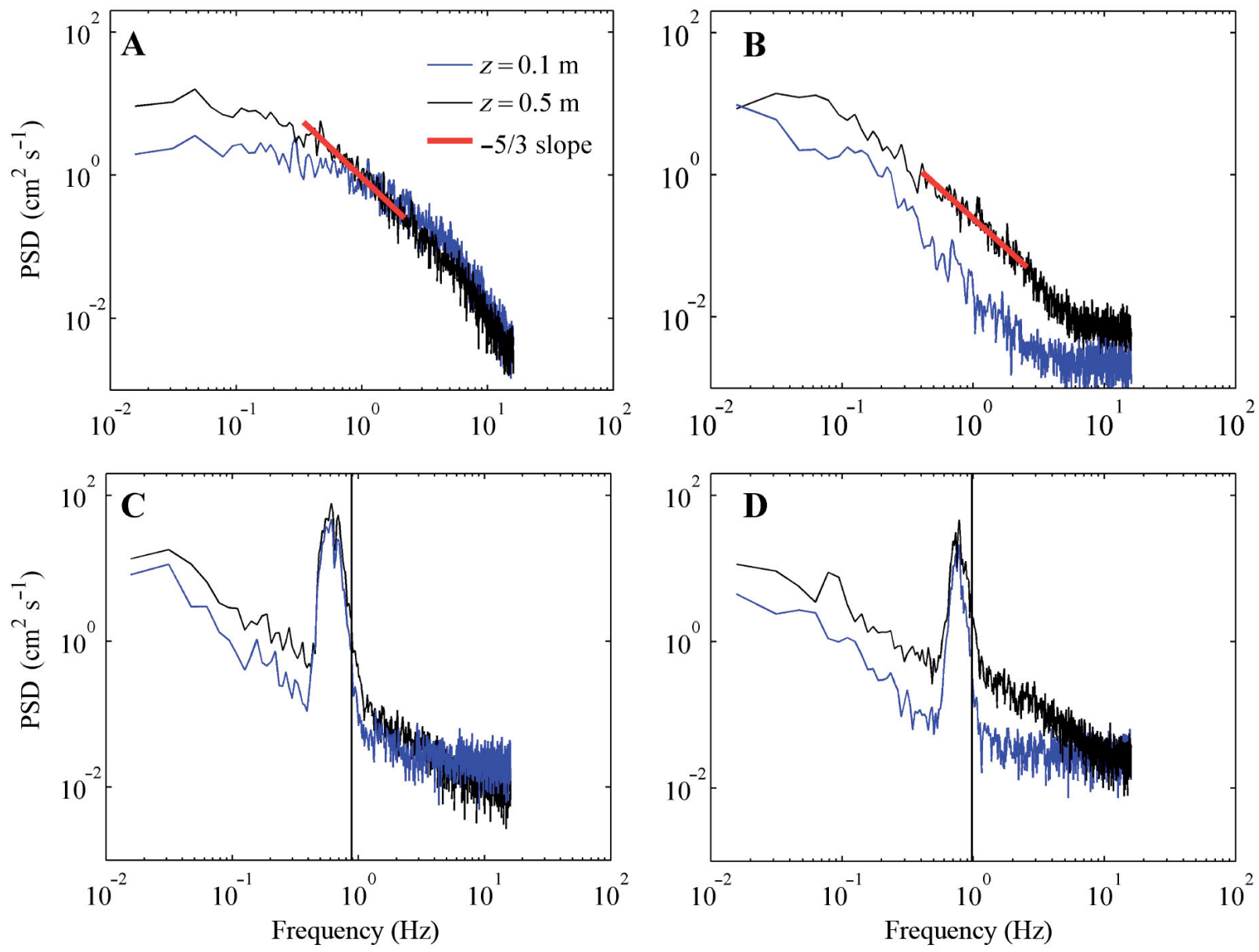

Fig. 8. Power spectral density (PSD) of horizontal velocity at the (A) bare site (horizontal component of the mean velocity $[\bar{u}]=$ $\left.9.7 \mathrm{~cm} \mathrm{~s}^{-1}\right)$ and (B) Site $2\left(\bar{u}=8.4 \mathrm{~cm} \mathrm{~s}^{-1}\right)$ during tidally dominated flow conditions. Spectra are formed by averaging 9 independent spectra of $\mathrm{n}=2048$ velocity records that occur within a 10 min time period. PSD for the (C) bare site $\left(\bar{u}=10.8 \mathrm{~cm} \mathrm{~s}{ }^{-1}\right.$, significant wave height $\left.\left[H_{\mathrm{s}}\right]=19 \mathrm{~cm}\right)$ and (D) mid-density eelgrass Site $2\left(\bar{u}=6.2 \mathrm{~cm} \mathrm{~s}^{-1}, H_{\mathrm{s}}=14 \mathrm{~cm}\right)$ during wave-dominated flow conditions. Vertical line represents the frequency at and above which wave motion is expected to be attenuated at $z$ (vertical distance above the seafloor) $=0.1 \mathrm{~m}$ according to linear wave theory. Flattening of the power density at high frequencies ( $>0.4 \mathrm{~Hz}$ in Panels B, C, and D) indicates that the noise floor of the instrument has been reached and the velocity signal is indistinguishable from noise 
reaching the seafloor for $f>\sqrt{g /(4 \pi h)}$ (Wiberg \& Sherwood 2008). At a given elevation above the seafloor, $z$, waves with $f>\sqrt{g /[4 \pi(h-z)]}$ will be attenuated.

PSD for frequencies between 0 and $2 \mathrm{~Hz}$ for both horizontal and vertical velocities are shown for the bare site in Fig. 9. These plots include the tidally dominated contributions to the spectra at small frequencies (i.e. $f<0.3 \mathrm{~Hz}$ ), as well as the wave component of the PSD, which typically spans the range $0.3<f<1 \mathrm{~Hz}$. Frequency analysis within the wave domain of the frequency spectra for the bare site indicate that there was a general trend of a reduction of wave energy near the seafloor for the vertical velocity, $S_{W w}$ PSD, but a fairly uniform distribution of wave energy throughout the water column for the horizontal, $S_{u u}$ PSD. Peak wave frequency at high tide was approximately $f=0.5 \mathrm{~Hz}(T=2 \mathrm{~s})$, but as the water depth decreased, peak wave frequency increased to approximately $f=1 \mathrm{~Hz}$, indicating a reduction in the peak wave period to $T=1 \mathrm{~s}$.

For Site 2, similar trends emerged in a reduction of vertical wave energy $\left(S_{w w}\right)$ within the seagrass bed compared to flow above the canopy (Fig. 10). There were also reductions in wave energy within the horizontal component of the velocity, $S_{u u}$ due to the wave-dampening effect that the eelgrass had on the flow. However, as is also shown in Fig. 8 for an individual spectrum, much of the reduction in wave energy occurred at the high frequencies within the wave band $(f>1 \mathrm{~Hz})$, which can be attributed both to attenuation due to the interaction with the seagrass and due to the natural attenuation of the waves with depth. The shorter period waves that formed over the seagrass bed (average $T=1.4 \pm 0.3 \mathrm{~s}$ ) tended to attenuate with depth to a greater extent than the longer period waves that formed over the bare site (average $T=1.7 \pm 0.4 \mathrm{~s}$ ), as predicted from linear wave theory. Also of note was the reduction in power density at low frequencies, $f<0.3 \mathrm{~Hz}$, indicating a reduction in the energy of the mean flow, $u$, within the canopy.

The wave-orbital velocity, $u_{\text {os }}$ at $z=0.5$ and $0.1 \mathrm{~m}$ was computed following Eq. (10), and estimates for each site are shown in Fig. 11. At the bare site, there was only a $3 \%$ difference in measured $u_{0 \mathrm{~s}}$ between the $z=0.5$ and $0.1 \mathrm{~m}$ elevations. At all 3 eelgrass sites there was an overall reduction in wave orbital motion by $20 \pm 5 \%$ within the canopy compared to above, and orbital velocities at the eelgrass sites were less than half that produced over the bare site. To determine the extent to which this orbital wave reduction within the eelgrass canopy was due to natural atten-
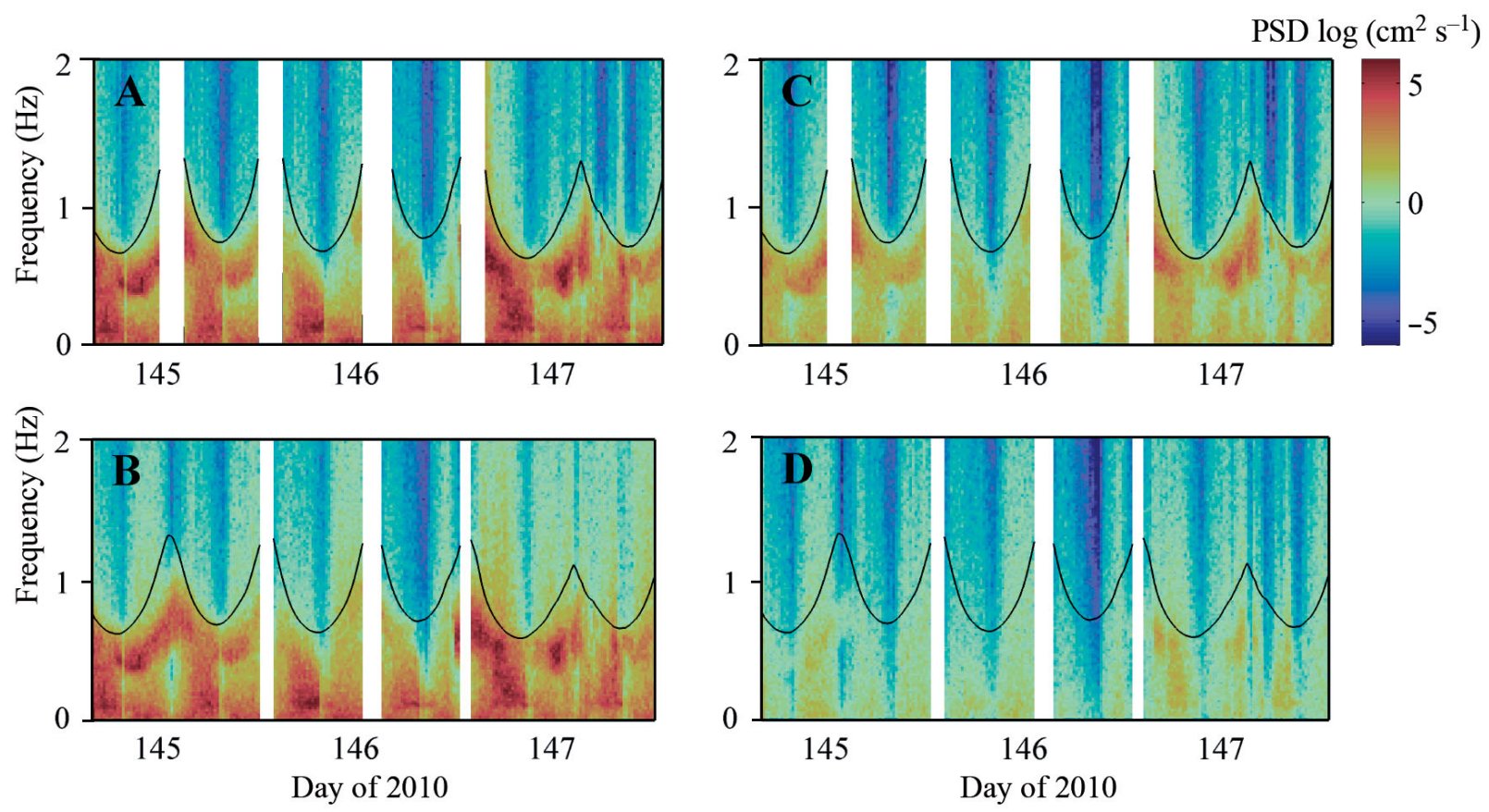

Fig. 9. Two-dimensional power spectral density (PSD) at the bare site of horizontal velocities (A) $S_{u u}$ at $z=0.5 \mathrm{~m}$ and (B) $S_{u u}$ at $z=0.1 \mathrm{~m}$, showing only minor attenuation of the wave frequency band. Two-dimensional PSD of vertical velocities (C) $S_{w w}$ at $z=0.5 \mathrm{~m}$ and (D) $S_{w w}$ at $z=0.1 \mathrm{~m}$, showing substantial attenuation of the wave frequency band, as predicted by wave theory. Black lines indicate $f=\sqrt{g /[4 \pi(h-z)]}$, where $g$ is gravitational acceleration, $h$ is water depth, $z$ is the vertical distance above the seafloor, and $f$ is the frequency at and above which linear wave theory predicts wave motion is attenuated. Regions with no data are during low tide when velocimeters had poor signal quality 

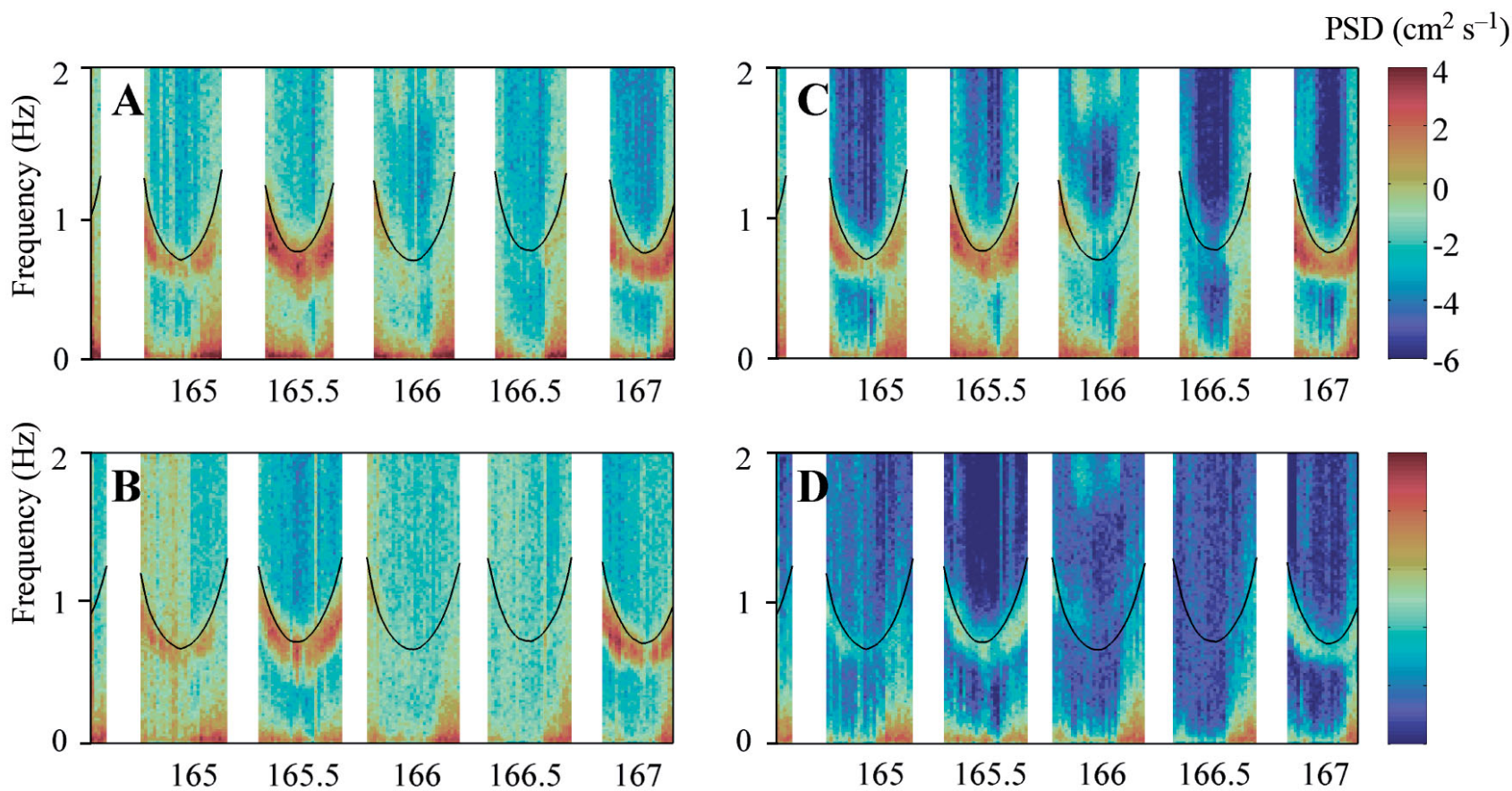

Fig. 10. Two-dimensional power spectral density (PSD) at Site 2 of horizontal velocities (A) $S_{\text {uu }}$ at $z=0.5 \mathrm{~m}$ and (B) $S_{\mathrm{uu}}$ at $z=$ $0.1 \mathrm{~m}$. Attenuation of the wave energy within the canopy primarily occurs at high frequency $(f)$ within the wave band of the spectrum. Two-dimensional PSD of vertical velocities (C) $S_{\mathrm{ww}}$ at $z=0.5 \mathrm{~m}$ and (D) $S_{\mathrm{ww}}$ at $z=0.1 \mathrm{~m}$, showing substantial attenuation of wave energy at all $f$-values within the wave band. Black lines indicate $f=\sqrt{g /[4 \pi(h-z)]}$, where $g$ is gravitational acceleration, $h$ is water depth, $z$ is the vertical distance above the seafloor, and $f$ is the frequency at and above which linear wave theory predicts wave motion is attenuated

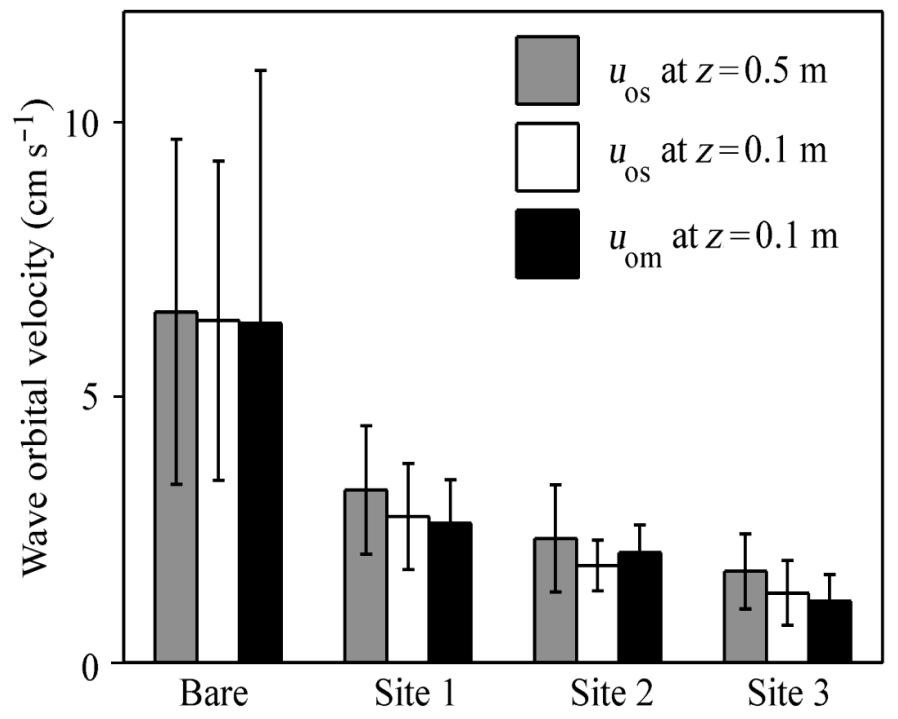

Fig. 11. Wave orbital velocities, $u_{\mathrm{os}}$ (Eq. 10), computed utilizing spectra of horizontal wave velocities, $S_{\tilde{u} \tilde{u}}$ and $S_{\tilde{V} \tilde{v},}$ at $z$ (vertical distance above the seafloor) $=0.5 \mathrm{~m}$ and $z=0.1 \mathrm{~m}$ and wave orbital velocities, $u_{\text {om }}$ (Eq. 12), at $z=0.1 \mathrm{~m}$, computed utilizing linear wave theory and estimates of freesurface displacements. Agreement between $u_{\mathrm{os}}$ and $u_{\mathrm{om}}$ at $z=0.1 \mathrm{~m}$ suggests wave velocity decay is primarily due to wave attenuation of high-frequency wave motion with depth, and not from interaction with the eelgrass uation with depth or due to interaction with the eelgrass bed, orbital velocities computed through local velocity spectra (Eq. 10) were compared to estimates of bottom wave-orbital velocities using pressure sensor measurements of displacement of the free surface. Using linear wave theory for small-amplitude, monochromatic waves, the horizontal component of orbital velocity, $u_{0}$, can be computed as:

$$
u_{\mathrm{o}}=\frac{\pi H}{T} \frac{\cosh (k z)}{\sinh (k h)} \cos (k x-\omega t)
$$

where $H$ is the rms of wave height (m), $\omega$ is the radian of wave frequency $\left(\mathrm{rad} \mathrm{s}^{-1}\right), x$ is the position in the wave orbital $(\mathrm{m})$, and $t$ is time $(\mathrm{s})$. As the velocities vary sinusoidally with the $x$ - and $t$-values throughout the wave period, the above equation can be simplified to the rms of the maximum orbital velocity when $|\cos (k x-\omega t)|=1$ :

$$
u_{\mathrm{om}}=\frac{\pi H \cosh (k z)}{T \sinh (k h)}
$$

Linear wave theory assumes the bed is frictionless; therefore, estimating wave velocity decay with depth using linear wave theory (Eq. 12) and comparing it to computed orbital velocities using local velocity mea- 
surements within the canopy (Eq. 10) should indicate the relative dampening of wave velocity due to frictional interaction with the seagrass canopy. Fig. 11 indicates there is good agreement between measured within-canopy orbital velocities and those estimated from linear wave theory, suggesting that within-canopy dampening of wave orbitals was primarily due to natural attenuation of high-frequency wave motion with depth and not from flow interaction with the eelgrass.

\section{Bottom shear stresses and suspended sediment}

The total stress imparted to the seafloor was quantified using a combined bottom shear stress, $\tau_{b}$, calculated as the square root of the sum of the squares of the shear stress due to currents, $\tau_{\text {current, }}$ and due to waves, $\tau_{\text {wave }}$ (Wiberg $\&$ Smith 1983) such that:

$$
\tau_{b}=\sqrt{\tau_{\text {wave }}^{2}+\tau_{\text {current }}^{2}}
$$

Wave shear stress was determined by:

$$
\tau_{\text {wave }}=\frac{1}{2} f_{w} \rho u_{b}^{2} \quad f_{w}=0.04\left[\frac{u_{b} T}{2 \pi k_{b}}\right]^{-0.25}
$$

such that $f_{\mathrm{w}}$ is the wave friction factor, $u_{\mathrm{b}}$ is the bottom orbital velocity, which can be approximated as $u_{0 \mathrm{~s}}$ measured near the seafloor (Wiberg \& Sherwood 2008 ), and $k_{\mathrm{b}}$ is the characteristic roughness length of the bottom, which is defined as $3 D_{84}$ (Lawson et al. 2007). $D_{84}$ is the sediment grain diameter such that $84 \%$ of grain diameters are smaller, and was measured to be $157 \mu \mathrm{m}$ at the bare site and $130 \mu \mathrm{m}$ within the seagrass canopy. Computation of the current shear stress within vegetation is not well described, especially in the presence of wave activity, but under unidirectional currents, a useful parameterization is through estimates of the near-bottom TKE (Stapleton \& Huntley 1995, Widdows et al. 2008):

$$
\tau_{\text {current }}=\rho u_{*_{\text {current }}}^{2}=0.19 \rho(\mathrm{TKE})
$$

Although waves can alter Reynolds stresses and TKE in the presence of a mean current (Grant \& Madsen 1979), our findings within South Bay suggest only minor alteration in the magnitude of TKE in the presence of small-amplitude wind waves; therefore, Eq. (15) can be reasonably applied.

Fig. 12 shows the magnitude of the total bottom shear stress at each site. At the bare site, median bottom shear stress was $\tau_{b}=0.17 \mathrm{~N} \mathrm{~m}^{-2}$, but within the eelgrass bed, median $\tau_{b} \leq 0.035 \mathrm{~N} \mathrm{~m}^{-2}$ at all sites.

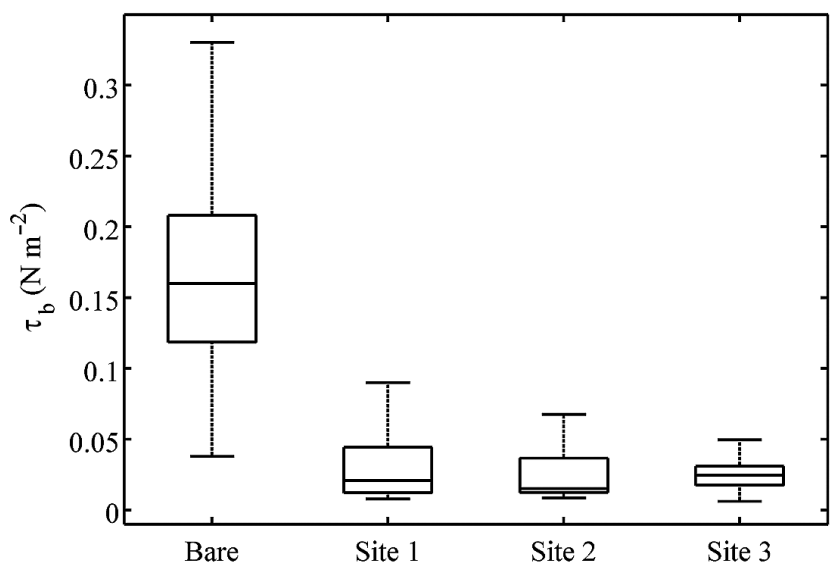

Fig. 12. Bottom shear stress $\left(\tau_{\mathrm{b}}\right)$ at each site calculated as the square of the sums of the wave and current bottom stresses. Horizontal line within the box indicates median $\tau_{\mathrm{b}}$, while the lower and upper edges of the box represent the 25th and 75th percentiles, respectively. Vertical lines extending from the box indicate the minimum and maximum measured $\tau_{\mathrm{b}}$

Although the critical shear stress that can initiate sediment resuspension was not directly quantified in South Bay, estimates within Hog Island Bay, which is directly adjacent to South Bay in the VCR, were performed by Lawson et al. (2007) and found to be $\tau_{\mathrm{cr}}=$ $0.04 \mathrm{~N} \mathrm{~m}^{-2}$ over unvegetated sites adjacent to seagrass beds. This value is in relative agreement with $\tau_{\text {cr }}=0.05 \mathrm{~N} \mathrm{~m}^{-2}$ found by Widdows et al. (2008) for sediments in the North Sea, where adjacent Zostera marina beds had a $\tau_{\mathrm{cr}}=0.07 \mathrm{~N} \mathrm{~m}^{-2}$. The increase in sediment stabilization within the $Z$. marina bed was found to be due to increased abundance of the microphytobenthos and lower densities of grazers. This suggests that $\tau_{\mathrm{cr}}=0.04 \mathrm{~N} \mathrm{~m}^{-2}$ is likely a reasonable estimate for unvegetated regions, and a conservative estimate for the eelgrass bed in South Bay. At the 3 eelgrass sites, measured $\tau_{b}$ was below the critical threshold for sediment entrainment during $80 \%$ of the sampling time period. However, $\tau_{b}$ at the unvegetated site was significantly larger than $\tau_{c r}$, suggesting that sediment resuspension was occurring during a significant fraction of the sampling period.

OBSs were deployed at each site, measuring SSCs at $z=0.1$ and $0.5 \mathrm{~m}$. SSC estimates at these elevations were averaged to create a mean SSC within the water column. Since flow and suspended sediment measurements were conducted at different time periods at each site, direct cross-site comparisons of SSC for the same time periods could not be conducted. Therefore, to determine if events of elevated magnitudes of bottom shear stress correlated to increases in

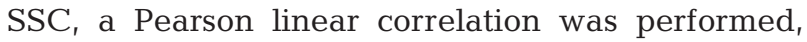


which is defined as the covariance of the 2 variables divided by the product of their standard deviations. Elevated SSC events were determined by taking the temporal mean of the $72 \mathrm{~h}$ data set from each site and locating periods of time when $\tau_{\mathrm{b}}$ was greater than its mean. At the bare site (mean $\mathrm{SSC}=56 \mathrm{mg} \mathrm{l}^{-1}$ ), there was a Pearson correlation coefficient of 0.72 between elevated levels of $\tau_{\mathrm{b}}$ and increased SSC. At Site 1 (mean SSC $=43 \mathrm{mg} \mathrm{l}^{-1}$ ), which is closest to the bare site, there was a correlation of 0.58 , while at Site 2 $\left(\right.$ mean SSC $=23 \mathrm{mg} \mathrm{l}^{-1}$ ) and Site 3 (mean SSC $=27 \mathrm{mg}$ $\mathrm{I}^{-1}$ ) there were correlation coefficients of 0.26 and 0.23 , respectively. Therefore, within the eelgrass meadow there was a decreased tendency for periods of high SSCs to correspond with periods of high bottom shear stress, suggesting that elevated levels of SSC within the seagrass bed were derived, in part, from non-local resuspension.

\section{DISCUSSION}

Zostera marina beds in this Virginia coastal bay were found to substantially lower overall mean currents compared to adjacent bare site flow conditions. Average velocities were 2 to 3 times higher at the bare site than at the eelgrass sites, without a substantial change in tidal forcing. In addition, near-bed flows were dramatically reduced, with mean velocity at $z=0.1 \mathrm{~m}$ at the bare site of $10.0 \mathrm{~cm} \mathrm{~s}^{-1}$, while average flows at the 3 eelgrass sites were $1.2 \mathrm{~cm} \mathrm{~s}^{-1}$, a $70 \%$ reduction compared to flow above the eelgrass canopy. Along the density gradient, ranging from 150 to 560 shoots $\mathrm{m}^{-2}$, the greatest flow reduction within the canopy compared to above the canopy occurred at Site 2, which was the mid-density site with $390 \pm$ 80 shoots $\mathrm{m}^{-2}$. The eelgrass at this site, however, also had a significantly higher mean $(28 \mathrm{~cm})$ and maximum blade length $(51 \mathrm{~cm})$ compared to the other two $Z$. marina sites. Although seagrass density has been found to play an important role in flow reduction (Ackerman \& Okubo 1993), the blade length is also important in modifying the canopy friction (Fonseca \& Fisher 1986), leading to a proportional reduction in fluid velocity (Gacia et al. 1999, Thompson et al. 2004). The smallest within-canopy flow reduction occurred at Site 3, which had the lowest eelgrass density and smallest average blade length. This suggests that both eelgrass density and blade length can have an impact on flow processes. Overall, the presence of seagrass structure serves to substantially reduce velocity magnitude as compared to the unvegetated seafloor (Hasegawa et al. 2008).
Tidally and wave-dominated flows were separated using the magnitude of the power density within the wave band of the frequency spectra. For tidally dominated flow conditions, the magnitude of the turbulent Reynolds stress typically decreased within the canopy compared to flow above, and within-canopy $\overline{u^{\prime} W^{\prime}}$ reductions increased with increasing seagrass density. The highest relative turbulence levels within the eelgrass bed were found at the lowest eelgrass density, Site 3, and were of similar magnitude within and above the canopy. This transition from low turbulence in high-density beds to elevated turbulence in low-density beds agrees with findings within other seagrass systems and laboratory measurements, which indicate enhanced turbulence due to stemgenerated wake turbulence (Nepf et al. 1997, Widdows et al. 2008). This enhanced turbulence can be intensified at the canopy-water interface (Abdelrhman 2003), where strong shear layers develop. Under wave-dominated flows, this relationship between turbulence intensity and seagrass density became less apparent, but both Reynolds stresses and TKE values were of similar magnitude with and without the presence of wave action. Quadrant analysis indicated that much of the turbulent motions within the canopy were dominated by sweeping events, where high-momentum fluid was transported downward into the canopy. These sweeps constituted $55 \%$ of the turbulent motion, compared to $32 \%$ for ejections of low-momentum fluid transported upwards out of the canopy. Strong sweeping motions into the canopy were also observed by Ghisalberti \& Nepf (2006), who found that sweeps were followed by weak ejection events $\left(u^{\prime}<0, w^{\prime}>0\right)$ which occurred at frequencies twice that of the dominant frequency of the coherent vortex formed at the top of the canopy.

\section{Wave attenuation due to interaction with the eelgrass canopy}

Significant wave heights and wave periods were computed from pressure records obtained from the ADVs at a sampling rate of $32 \mathrm{~Hz}$. Wave periods at all sites ranged between 1 and $2 \mathrm{~s}$, representing windgenerated gravity waves. There was a 45 to $70 \%$ reduction in average $H_{\mathrm{s}}$ at the eelgrass sites compared to the bare site. For both the bare and eelgrass sites, the majority of energy lost within the wave band occurred at high wave frequencies, $\geq 1 \mathrm{~Hz}$. This is in general agreement with wave theory, which predicts that waves with $f>\sqrt{g /(4 \pi h)}$ will be attenu- 
ated before reaching the bottom (Wiberg \& Sherwood 2008). Mean wave periods were $T=1.7 \pm 0.4 \mathrm{~s}$ and $T=1.4 \pm 0.3 \mathrm{~s}$ at the bare and eelgrass sites, respectively. As evident from PSD graphs, waves were not monochromatic and typically spanned a range of frequencies between $f=0.3$ and $1 \mathrm{~s}^{-1}$. At the bare site, measured mean wave orbital velocities were within $3 \%$ of each other at both $z=0.5$ and $0.1 \mathrm{~m}$. With the presence of eelgrass structure, the horizontal orbital velocities were found to decrease by approximately $20 \%$ within the canopy versus above. That shorter period waves formed over the eelgrass canopy suggests that natural wave attenuation with depth was a major contributing factor in the measured reduction in orbital velocities within the canopy. However, little reduction in low-frequency wave motion within the canopy indicates that oscillatory flows were also effective at penetrating the eelgrass canopy for longer period waves. This suggests that storm events, which tend to increase $H_{\mathrm{s}}$ and $T$ in combination with storm surge (Chen et al. 2005), may be effective in generating oscillatory flows through the seagrass canopy, increasing bottom shear stresses and ultimately leading to sediment resuspension. This agrees with the results of Bradley \& Houser (2009), who found that the ability for seagrasses to attenuate wave energy decreases as wave heights increase, but that seagrasses also serve as a low-pass filter where higher frequencies in the spectra tend to be more attenuated. Their results also suggest that the rate of energy dissipation is not uniform over a range of wave frequencies, and waves at higher frequencies are attenuated, but waves at lower frequencies are less affected by the seagrass.

\section{Bottom shear stress and sediment dynamics}

Total bottom shear stress was estimated by summing contributions from orbital wave motion due to waves and turbulence from the mean current. Overall, bottom shear stress at the bare site was found to be $\tau_{\mathrm{b}}=0.17 \pm 0.08 \mathrm{~N} \mathrm{~m}^{-2}$, which was 5 times greater than at any of the eelgrass sites. Within the eelgrass canopy the mean $\tau_{\mathrm{b}}$ at the 3 sites ranged between $0.025 \pm 0.02$ and $0.032 \pm 0.03 \mathrm{~N} \mathrm{~m}^{-2}$. A conservative estimate of the critical shear stress for sediment erosion was $\tau_{\mathrm{cr}}=0.04 \mathrm{~N} \mathrm{~m}^{-2}$, which was measured in an adjacent coastal bay with similar water depth and sediment characteristics (Lawson et al. 2007). Bottom shear stress was found to be below the critical bottom stress threshold for erosion $80 \%$ of the time within the eelgrass meadow. In the absence of eelgrass, depth-averaged SSC $=56 \mathrm{mg} \mathrm{l}^{-1}$, and elevated levels of SSCs were well correlated throughout the water column with periods of high bottom shear stress (Pearson linear correlation coefficient $=0.72$ ). However, with the addition of eelgrass structure, increases in depth-averaged suspended sediment were no longer well correlated with enhanced bottom shear stress. Correlation between $\tau_{\mathrm{b}}$ and elevated SSC occurred most closely at Site 1 (mean SSC $=43 \mathrm{mg}$ $\mathrm{l}^{-1}$, correlation coefficient $=0.58$ ), which is located closest to unvegetated sites within the bay and the edge of the eelgrass meadow (Fig. 1), where sediment resuspension is expected to be most pronounced. Further from regions devoid of eelgrass, correlations between elevated $\tau_{\mathrm{b}}$ and SSC drop considerably, where at Site 2 (mean $\mathrm{SSC}=23 \mathrm{mg} \mathrm{l}^{-1}$ ) and Site 3 (mean SSC $=27 \mathrm{mg} \mathrm{l}^{-1}$ ) correlation coefficients were 0.26 and 0.23 , respectively. This suggests that suspended sediment measured within the canopy was, to some magnitude, advected into the canopy from non-vegetated regions of the bay. Although wave activity has been shown to be a dominant driver initiating the suspension of sediment within these shallow coastal bays, previous studies have shown that wave activity alone does not necessarily induce the transport of sediment (Heller 1987). Rather, the combination of both waves and currents acts to distribute sediment throughout the seagrass bed. The stress exerted by wave motion acts to suspend sediment above the seafloor, but, ultimately, unidirectional currents will cause a net transport of sediment, even if such a unidirectional current alone produces conditions below the threshold to initiate sediment suspension.

Overall, our results indicate that turbulence, wave heights, and wave orbital velocities were reduced in magnitude by the eelgrass canopy. This resulted in lowered suspended sediment within the eelgrass meadow as compared to adjacent unvegetated areas. In addition, between 2003 through 2009, monthly turbidity levels within the vegetated areas were found to be significantly lower than levels outside of the vegetated areas under summer conditions (Orth et al. 2012). Within the eelgrass canopy, SSC showed significant decreases over time, with median SSC decreasing approximately $75 \%$ between 2003 and 2009, and coincided with increased retention of fine sediments. These findings relate well with trends found in previous studies where flow reduction by seagrass meadows ranged from 25 to $80 \%$ (Koch \& Gust 1999, Nepf 1999, Lacy \& Wyllie-Echeverria 2011) and turbulence was reduced 30 to $50 \%$ (Granata et al. 2001). In a study by Gruber \& Kemp (2010) with a 
similar current and wave regime as that in our study, reductions in SSC of up to $60 \%$ were found, which varied directly with seagrass biomass via seasonal senescence of a Stuckenia pectinata meadow. Our findings using different density sites within the same eelgrass bed suggest the opposite trend of lower SSC values at less dense seagrass sites. These opposing trends are likely due to site location within the meadow and local exposure to wind and wave activity. Locations that were further from the canopy edge and locations where waves propagated further distances across the eelgrass canopy had greater reductions in flow and suspended sediment. These findings suggest that seagrass density and meadow size both play roles in sediment suspension.

There is evidence to suggest that seagrass patches below a minimum size, and possibly locations close to the canopy edge, act to enhance near-bed turbulence and cause scouring (Heller 1987, Fonseca \& Koehl 2006). Once the bed reaches a minimum density and patch width, turbulence reduction occurs, switching the local flow environment from erosional to depositional. Although it is still unclear what minimum size causes this transition, our findings suggest that the expansion of the eelgrass canopy within South Bay has altered the hydrodynamics from a net erosional environment to one that promotes deposition of suspended sediment. This has enhanced light penetration throughout the water column and created a positive feedback for eelgrass growth.

Acknowledgements. We thank E. Whitman, A. Schwarzschild, C. Buck, and D. Boyd for field assistance, and J. Bricker for helpful discussions regarding wave-turbulence decomposition. This research was funded by, and some data were provided by, a Virginia Coast Reserve Long-Term Ecological Research grant by the National Science Foundation (NSF-DEB 0621014，BSR-8702333-06, DEB-9211772, DEB94118974, DEB-0080381). J.C.R.H. was supported through an NSF graduate research fellowship (DGE-0809128).

\section{LITERATURE CITED}

Abdelrhman MA (2003) Effect of eelgrass Zostera marina canopies on flow and transport. Mar Ecol Prog Ser 248: $67-83$

Ackerman JD, Okubo A (1993) Reduced mixing in a marine macrophyte canopy. Funct Ecol 7(3):305-309

Agawin NSR, Duarte CM (2002) Evidence of direct particle trapping by a tropical seagrass meadow. Estuaries 25: 1205-1209

Bennet SJ, Best JL (1996) Mean flow and turbulence structure over fixed ripples and the ripple-dune transition. In: Ashworth PJ, Bennet SJ, Best JL, McLelland SJ (eds) Coherent flow structures in open channels. John Wiley, New York, NY, p 281-304
Bouma TJ, Friedrichs M, Klaassen P, van Wesenbeeck BK and others (2009) Effects of shoot stiffness, shoot size and current velocity on scouring sediment from around seedlings and propagules. Mar Ecol Prog Ser 388: 293-297

Bradley K, Houser C (2009) Relative velocity of seagrass blades: Implications for wave attenuation in low-energy environments. J Geophys Res Earth Surface 114:1-13

Bricker JD, Monismith SG (2007) Spectral wave-turbulence decomposition. J Atmos Ocean Technol 24:1479-1487

Carr J, D'Odorico PD, McGlathery K, Wiberg P (2010) Stability and bistability of seagrass ecosystems in shallow coastal lagoons: role of feedbacks with sediment resuspension and light attenuation. J Geophys Res 115 doi: 10.1029/2009JG001103

Chen Q, Zhao H, Ju K, Douglass SL (2005) Prediction of wind waves in a shallow estuary. J Waterw Port Coast Ocean Eng 131:137-148

Chen SN, Sanford LP, Koch E, Shi F, North EW (2007) A nearshore model to investigate the effects of seagrass bed geometry on wave attenuation and suspended sediment transport. Estuar Coast 30:296-310

> de Boer WF (2007) Seagrass-sediment interactions, positive feedbacks and critical thresholds for occurrence: a review. Hydrobiologia 591:5-24

Dean RG, Dalrymple RA (1991) Water wave mechanics for engineers and scientists. World Scientific, Singapore

Denny MW (1988) Biology and the mechanics of the waveswept environment. Princeton University Press, Princeton, NJ

Fagherazzi S, Wiberg P (2009) Importance of wind conditions, fetch, and water levels on wave-generated shear stresses in shallow intertidal basins. J Geophys Res 114:F03022 doi:10.1029/2008JF001139

> Fonseca MS, Cahalan JA (1992) A preliminary evaluation of wave attenuation by four species of seagrass. Estuar Coast Shelf Sci 35:565-576

> Fonseca MS, Fisher JS (1986) A comparison of canopy friction and sediment movement between four species of seagrass with reference to their ecology and restoration. Mar Ecol Prog Ser 29:15-22

- Fonseca MS, Koehl MAR (2006) Flow in seagrass canopies: the influence of patch width. Estuar Coast Shelf Sci 67: $1-9$

Fonseca MS, Fisher JS, Zieman JC, Thayer GW (1982) Influence of the seagrass, Zostera marina L., on current flow. Estuar Coast Shelf Sci 15:351-364

> Gacia E, Duarte CM (2001) Sediment retention by a Mediteranean Posidonia oceanica meadow: the balance between deposition and resuspension. Estuar Coast Shelf Sci 52:505-514

Gacia E, Granata TC, Duarte CM (1999) An approach to measurement of particle flux and sediment retention within seagrass (Posidonia oceanica) meadows. Aquat Bot 65:255-268

Ghisalberti M, Nepf HM (2002) Mixing layers and coherent structures in vegetated aquatic flows. J Geophys Res 107 (2) 3011 doi:10.1029/2001JC000871

Ghisalberti M, Nepf H (2006) The structure of the shear layer in flows over rigid and flexible canopies. Environ Fluid Mech 6:277-301

Granata TC, Serra T, Colomer J, Casamitjana X, Duarte CM, Gacia E (2001) Flow and particle distributions in a nearshore seagrass meadow before and after a storm. Mar Ecol Prog Ser 218:95-106 
Grant WD, Madsen OS (1979) Combined wave and current interaction with a rough bottom. J Geophys Res 84: 1797-1808

Grass A (1971) Structural features of turbulent flow over smooth and rough boundaries. J Fluid Mech 50:233-255

Gross TF, Nowell AR (1983) Mean flow and turbulence scaling in a tidal boundary layer. Cont Shelf Res 2:109-126

Gruber RK, Kemp WM (2010) Feedback effects in a coastal canopy-forming submersed plant bed. Limnol Oceanogr $55: 2285-2298$

Hasegawa N, Hori M, Mukai H (2008) Seasonal changes in eelgrass functions: current velocity reduction, prevention of sediment resuspension, and control of sedimentwater column nutrient flux in relation to eelgrass dynamics. Hydrobiologia 596:387-399

Heller DY (1987) Sediment transport in seagrass beds. MS thesis, University of Virginia, Charlottesville, VA

Jing L, Ridd PV (1996) Wave-current bottom shear stresses and sediment resuspension in Cleveland Bay, Australia. Coast Eng 29:169-186

Koch E, Gust G (1999) Water flow in tide- and wavedominated beds of the seagrass Thalassia testudinum. Mar Ecol Prog Ser 184:63-72

Koch E, Ackerman JD, Verduin J, van Keulen M (2006) Fluid dynamics in seagrass ecology-from molecules to ecosystems. In: Seagrasses: biology, ecology and conservation. Springer, Amsterdam, p 193-225

Lacey RWJ, Roy AG (2008) Fine-scale characterization of the turbulent shear layer of an instream pebble cluster. J Hydraul Eng 134 doi:10.1061/(ASCE)0733-9429(2008) 134:7(1925)

Lacy JR, Wyllie-Echeverria S (2011) The influence of current speed and vegetation density on flow structure in two macrotidal eelgrass canopies. Limnol Oceanogr Fluids Environ 1:38-55

Lawson SE, Wiberg PL, McGlatherty KJ, Fugate DC (2007) Wind-driven sediment suspension controls light availability in a shallow coastal lagoon. Estuar Coast 30: 102-112

Lu SS, Willmarth WW (1973) Measurements of the structure of the Reynolds stress in a turbulent boundary layer. J Fluid Mech 60:481-571

Madsen JD, Chambers PA, James WF, Koch EW, Westlake DF (2001) The interaction between water movement, sediment dynamics and submersed macrophytes. Hydrobiologia 444:71-84

McGlathery K, Anderson IC, Tyler AC (2001) Magnitude and variability of benthic and pelagic metabolism in a temperate coastal lagoon. Mar Ecol Prog Ser 216:1-15

Nepf HM (1999) Drag, turbulence, and diffusion in flow through emergent vegetation. Water Resour Res 35: 479-489

> Nepf HM, Vivoni ER (2000) Flow structure in depth-limited, vegetated flow. J Geophys Res 105:28547-28557

Nepf HM, Sullivan JA, Zavistoski RA (1997) A model for

Submitted: February 28, 2011; Accepted: May 24, 2011 diffusion with emergent vegetation. Limnol Oceanogr 42:1735-1745

Nepf H, Ghisalberti M, White B, Murphy E (2007) Retention time and dispersion associated with submerged aquatic canopies. Water Resour Res 43:W04422 doi: 10.1029/ 2006WR005362

Orth RJ, Luckenbach ML, Marion SR, Moore KA, Wilcox DJ (2006) Seagrass recovery in the Delmarva coastal bays, USA. Aquat Bot 84:26-36

Orth RJ, Moore KA, Marion SR, Wilcox DJ, Parrish DB (2012) Seed addition facilitates eelgrass recovery in a coastal bay system. Mar Ecol Prog Ser 448:177-195

> Peterson CH, Luettich RA, Micheli F, Skilleter GA (2004) Attenuation of water flow inside seagrass canopies of differing structure. Mar Ecol Prog Ser 268:81-92

Sand-Jensen K, Borum J (1991) Interactions among phytoplankton, periphyton, and macrophytes in temperate fresh-waters and estuaries. Aquat Bot 41:137-175

Short FT, Muehlstein LK, Porter D (1987) Eelgrass wasting disease: cause and recurrence of a marine epidemic. Biol Bull 173:557-562

Stapleton KR, Huntley DA (1995) Seabed stress determinations using the inertial dissipation method and the turbulent kinetic energy method. East Afr Med J 20:807-815

Thompson CEL, Amos CL, Umgiesser G (2004) A comparison between fluid shear stress reduction by halophytic plants in Venice Lagoon, Italy and Rustico Bay, Canada analyses of in situ measurements. J Mar Syst 51:293-308

Trowbridge JH (1998) On a technique for measurement of turbulent shear stress in the presence of surface waves. J Atmos Ocean Technol 15:290-298

Verduin JJ, Backhaus JO (2000) Dynamics of plant-flow interactions for the seagrass Amphibolis antarctica: field observations and model simulations. Estuar Coast Shelf Sci 50:185-204

Ward LG, Kemp WM, Boynton WR (1984) The influence of waves and seagrass communities on suspended particulates in an estuarine embayment. Mar Geol 59:85-103

Wiberg PL, Sherwood CR (2008) Calculating wavegenerated bottom orbital velocities from surface-wave parameters. Comput Geosci 34:1243-1262

Wiberg P, Smith JD (1983) A comparison of field data and theoretical models for wave current interactions at the bed on the continental shelf. Cont Shelf Res 2:147-162

> Widdows J, Pope ND, Brinsley MD, Asmus H, Asmus RM (2008) Effects of seagrass beds (Zostera noltii and $Z$. marina) on near-bed hydrodynamics and sediment resuspension. Mar Ecol Prog Ser 358:125-136

Worcester SE (1995) Effects of eelgrass beds on advection and turbulent mixing in low current and low shoot density environments. Mar Ecol Prog Ser 126:223-232

Zimmerman RC, Reguzzoni JL, Alberte RS (1995) Eelgrass (Zostera marina L.) transplants in San Francisco Bay: role of light availability on metabolism, growth and survival. Aquat Bot 51:67-86

Proofs received from author(s): October 11, 2011 